\title{
$\mathrm{M}|\mathrm{R}| \mathrm{S}$ Internet Journal Nitride Semiconductor Research
}

\section{Review of polarity determination and control of GaN}

\author{
M. Sumiya ${ }^{12}$ and S. Fuke ${ }^{1}$ \\ ${ }^{1}$ Shizuoka Univeristy, \\ ${ }^{2}$ CREST-JST,
}

(Received Friday, November 21, 2003; accepted Monday, February 9, 2004)

Polarity issues affecting III-V nitride semiconductors are reviewed with respect to their determination and control. A set of conditions crucial to the polarity control of GaN is provided for each of the following growth techniques; molecular beam epitaxy (MBE), pulsed laser deposition (PLD) and hydride vapor phase epitaxy (HVPE). Although GaN films might have been deposited by identical growth methods using the same buffer layer technologies, there is often a conflict between the resulting polarities achieved by different research groups. In this paper, we present the implications of the conditions used in each of the processes used for two-step metalorganic chemical vapor deposition (MOCVD), demonstrating systematic control of the polarity of GaN films on sapphire substrates. The potential for confusion in polarity control will be explained, taking into account the implications clarified in our studies. The correlation between the polarity and the growth conditions will be discussed in order to provide a mechanism for the determination and control of the crystal polarity during the growth of GaN films.

\section{Introduction}

The polarity of III-V nitride semiconductors is a critical issue that has hindered improvements in nitride materials and the performance of devices. The quality of the wurtzite GaN films shown in Figure 1 can be varied by the polarity, because both the incorporation of impurities and the formation of defects are related to the growth mechanism, which in turn depends on the polarity of the surface. The occurrence of a two dimensional electron gas (2DEG) and the optical properties of hetero-structures of nitride-based materials are influenced by the internal field effects caused by spontaneous and piezo-electric polarizations. Devices in all of the III-V nitrides are fabricated on polar $\{0001\}$ surfaces. Consequently, their characteristics depend on whether the GaN films exhibit Ga- $(+c)$ or $\mathrm{N}-(-\mathrm{c})$ face polarity. Therefore, it is very important to be able to determine and control the polarity of GaN.

Nitride films have conventionally been grown on sapphire substrates by using a number of growth techniques, such as two-step metallorganic chemical vapor deposition (MOCVD) [1], molecular beam epitaxy (MBE), pulsed laser deposition (PLD) and hydride vapor phase epitaxy (HVPE). Figure 2 shows optical microscope images for our MOCVD-GaN films with both smooth and hexagonal-facetted surfaces, which are due to $+\mathrm{c}$ and $-\mathrm{c}$ polarity, respectively. The results of our study compare well with the standard frameworks for the polarity provided by Hellman [2] and the resulting GaN samples are acceptable within this context.

Some researchers have classified the polarity of GaN films by the growth method used to obtain them, in that films grown by MOCVD and MBE have $+\mathrm{c}$ and $-\mathrm{c}$ polarity, respectively. In addition, nitridation of sapphire substrate has often been regarded as a way to obtain -c GaN films. However, different groups using the same growth technique have sometimes found that there are conflicts between the polarities that result from their experiments. When GaN films are grown by $\mathrm{MBE}$ (in which the nitridation process is commonly used) $+\mathrm{c}$ GaN films are the likely outcome under III-rich conditions. On the other hand, although the sapphire substrate was not intentionally nitrided, a hexagonal-facetted surface (indicating - c polarity) was observed for a $\mathrm{GaN}$ film on a thin GaN buffer layer grown by MOCVD and reported by Nakamura [3]. In another report by Uchida et al., a smooth surface (indicating $+c$ polarity) was obtained for a GaN film grown on a thicker buffer layer by MOCVD, even though the substrate was intentionally nitrided [4]. These confusions in controlling the polarity are a feature of the growth experience of many research groups. 
We have studied the role of the LT-buffer layer and the implications of each part of the process for the growth of GaN films by two-step MOCVD. The conditions used to treat the substrate and the deposition and annealing of the LT-buffer layer have been found to correlate with the polarity of the grown layers. Through these studies, 'recipes' to control the polarity of the layers have been suggested. Indeed, the polarity can be managed from $+c$ through to $-\mathrm{c}$, including mixed polarity layers, by systematically varying the conditions used in the MOCVD process (Sec. 4). This paper will critically review the status of polarity control for the MBE, PLD and HVPE growth methods, as published in the literature. General conditions that are decisive for the determination of polarity are itemized for each growth method. Comparing the recipes used in MOCVD growth with the features identified for the other methods, we will examine whether or not the implications derived from our evaluation of the MOCVD process are equivalent to those noted for the other methods. The correlation between polarity and the growth conditions will be discussed in order to clarify the various confusions experienced in the determination of polarity during $\mathrm{GaN}$ growth.

In Sec. 2, techniques for evaluating the polarity are summarized in chronological order, and their specific features are identified. We used coaxial impact collision ion scattering spectroscopy [5] (CAICISS) to characterize the polarity. The important features and the advantages of CAICISS are mentioned. The case of InGaN multi-quantum wells is examined to demonstrate the potential of CAICISS analysis. In Sec. 3, the correlation between the polarity and the growth conditions in terms of substrate treatment and buffer layer preparation is summarized for GaN films deposited by MBE, PLD, and HVPE. In Sec. 4, variations in the LT-buffer layer depending on the growth conditions in MOCVD are examined with respect to controlling the polarity. While discussing the implications of each growth process in MOCVD, 'recipes' to manage the polarity of the GaN films are proposed. By comparing these recipes with the relevant details of other techniques, it will be concluded that the polar structures at the interfaces of both the sapphire substrate and the annealed LT-buffer layer are the most important aspects of polarity management. Our focus moves on in Sec. 5 to a study of the polaritydependence of the properties of $\mathrm{GaN}$ films and of device performance. The dependence of the properties of $\mathrm{GaN}$ on the polarity properties is elucidated with respect to both impurity incorporation and defect formation. The effect on device performance of the internal electrical field due to the polarity in the material is reviewed, focusing on the interface between the metal and the III-
V nitride semiconductors. Our work is finally summarized in Sec. 6.

\section{Characterization of GaN polarity}

We selected CAICISS analysis to determine the polarity of $\mathrm{GaN}$ out of the many techniques that are available. After summarizing the various techniques and their features, the advantages of CAICISS are introduced by presenting a study of InGaN single quantum well (SQW) using CAICISS in this section.

\subsection{Notation of GaN polarity}

When three of the bonds on a Ga atom with tetrahedral coordination face towards the substrate, the polarity is typically called Ga-face. In contrast, when three bonds face in the growth direction, the material is termed Nface, as shown in Figure 1. There are four possible surface structures in wurtzite III-V nitrides, considering both the termination atom and the crystallographic polarity, e.g., Ga-terminated N-face polarity. Although the terms Ga- and N-face, Ga- and N-termination or Aand $\mathrm{B}$-face have been used as a sign of polarity, it is very complicated to distinguish the polarity from the termination atoms, though Seelmann-Eggebert et al. do use 'termination' to represent the polarity [6]. Furthermore, since AlN, InN and their alloys also need to be considered, the polar structure with the three bonds of III-atom facing toward the substrate is defined as $+c$ polarity and the opposite as $-\mathrm{c}$ polarity in this paper. The termination atoms are not specified unless they are mentioned explicitly.

\subsection{Spontaneous polarization of nitride semicon- ductor material}

The wurtzite symmetry is too low to cause an equivalent electronic structure of charge density for all 4 bonds. Even for a wurtzite material with ideal lattice constant ratio of 'c/a', spontaneous polarization may still occur. In hexagonal $\mathrm{GaN}$, the strong ionicity between $\mathrm{Ga}-\mathrm{N}$ bonds results in larger spontaneous polarization along the c-axis and slightly shorter value of c/a ratio (The lattice constants of strain-free hexagonal $\mathrm{GaN}$ are $\mathrm{a}=$ 3.189 and $\mathrm{c}=5.185 \AA$.). The amount of sheet charge density induced by the spontaneous polarization is considered to be $-0.029 \mathrm{C} / \mathrm{m}^{2}$ [7] corresponding to $\sim 3 \mathrm{MV} /$ $\mathrm{cm}$ of internal electric field (conversion using the dielectric constant of $\mathrm{GaN}$ ). Actually, the band profile of the $\mathrm{GaN}$ must be flat due to the influence of both the surface states and the carriers, except in the surface region [8]. The surface charge density caused by the spontaneous polarization is estimated to be in the order of $10^{13} \mathrm{~cm}^{-2}$. Hence, if a surface state density of approximately $10^{14}$ $10^{15} \mathrm{~cm}^{-2}$ is reduced down to $10^{13} \mathrm{~cm}^{-2}$ by a certain surface treatment for GaN thin films $(\sim 100 \mathrm{~nm})$ with a car- 
rier density of less than $10^{17} \mathrm{~cm}^{-3}$, it is expected that the depth of the depletion layer from the surface should extend to approximately $100 \mathrm{~nm}$, which is comparable to the film thickness.

There is a positive or a negative polarization charge at each interface of the multi-quantum-wells (MQWs) that are used as the active layer of LEDs and LDs. The band decline of a very thin well and barrier layer should become mutually opposite, taking into account the flatness of the Fermi level and the depth of the depletion layer. The strength of the electric field within the InGaN active layer has been estimated experimentally to be $0.35 \mathrm{MV} / \mathrm{cm}$ from the peak shift of the PL spectra of MQWs with various thickness of wells [9]. Since the spontaneous polarizations of $\mathrm{InN}$ and $\mathrm{GaN}$ are very close, the internal electric field in the InGaN/GaN system is mainly caused by the difference in their piezoelectric polarizations; $\mathrm{e}_{33}\left(\mathrm{GaN}: \sim 0.4 \mathrm{C} / \mathrm{m}^{2}, \mathrm{InN}: \sim 1 \mathrm{C} /\right.$ $\left.\mathrm{m}^{2}[10]\right)$. In contrast, the formation of a $2 \mathrm{DEG}$ of up to $10^{13} \mathrm{~cm}^{-2}$ at the interface of the AlGaN/GaN system cannot be explained by piezoelectric polarization alone. The effects of spontaneous polarization must be taken into consideration, owing to the large difference in the spontaneous polarizations between $\operatorname{AlN}\left(-0.081 \mathrm{C} / \mathrm{m}^{2}\right)$ and GaN [11].

Thus, a band profile of a hetero-structure of III-V nitrides can be modified by a combination of both the piezoelectric and spontaneous polarizations of the materials (discussed in Sec. 5). Since the influence of spontaneous polarization is sufficiently large in III-nitride system, the evaluation of the polarity is also important when designing for optimum device performance.

\subsection{History of polarity evaluation}

\subsubsection{4-1994: XPS and thermal stability}

Techniques that have been used for the evaluation of GaN polarity are listed in chronological order in Table (a). The relationship between the growth conditions (and also the growth method) and the resulting polarity is presented. The first characterization results came out in 1988, two years after better quality GaN films were deposited by the development of the LT-buffer layer. Sasaki et al. deposited GaN films on both the Si and C faces of $6 \mathrm{H}-\mathrm{SiC}$ substrates by MOCVD, and their polarities were determined by the dependence of the Ga signal intensity detected with angle-resolved x-ray photoelectron spectroscopy (XPS) [12]. The surface morphologies of the samples on $\mathrm{Si}$ - and $\mathrm{C}$-face $\mathrm{SiC}$ substrates were either featureless or hexagonal facetted. $\mathrm{GaN}$ films deposited on Si- and C-face $6 \mathrm{H}-\mathrm{SiC}$ substrates were expected to show $+\mathrm{c}$ and $-\mathrm{c}$ polarity, respectively, according to the relationship of the electron negativity of Si and C [13] [14]. However, they deter- mined the polarity of the former and the latter as -c and $+c$ polarity, respectively. This misjudgment might possibly have been caused by an immature understanding of oxygen adsorption on the polar surface of GaN (refer to Sec. 5.1).

7 years later, Sun et al. found that a GaN film deposited on the $\mathrm{Si}$-face of a $6 \mathrm{H}-\mathrm{SiC}$ substrate was unstable in an $\mathrm{H}_{2}$ ambient at $600^{\circ} \mathrm{C}$ [15]. This $\mathrm{GaN}$ sample was determined to have $+c$ polarity due to the electron negativity of $\mathrm{Si}$ and $\mathrm{C}$, in contrast with Sasaki's conclusion. We also confirmed the instability of $+\mathrm{c} G a N$ under these conditions [16]. However, we felt that the window of the conditions used for annealing temperature, time and gas ambient seemed to be very narrow. Therefore, this technique was difficult to use generally for determining the polarity. In 2001, Koukitsu et al. measured the decomposition rate of $+\mathrm{c}$ and $-\mathrm{c}$ GaN samples in $\mathrm{N}_{2}$ or $\mathrm{H}_{2}$ gas ambients using the microgravity method [17]. $\mathrm{GaN}$ with $+\mathrm{c}$ polarity decomposed faster at lower temperatures $\left(800-850^{\circ} \mathrm{C}\right)$ than $\mathrm{GaN}$ with $-\mathrm{c}$ polarity $(900-$ $950^{\circ} \mathrm{C}$ ), which was consistent with Sun's report and Hellman's standard framework.

\subsubsection{6: CBED}

The investigation of polarity began intensively in '96, when the first GaN blue laser diode was developed using MOCVD and when better quality GaN was also being attempted to be grown by MBE. A convergence beam of electron diffraction (CBED) technique based on TEM [18] [19] was mainly used to determine the polarity by studying asymmetric diffraction spots of (0002) and $(000 \overline{1})$. The quality of the GaN material must be sufficiently high in order to achieve clear asymmetric diffraction spots. Important aspects concerning polarity were identified through CBED observations of several kinds of GaN films in the following work;

1. MOCVD- and MBE-GaN films were likely to have $+\mathrm{c}$ and mixed polarity-containing inversion domains (IDs), respectively [20].

2. Nitridation of the sapphire substrate in MOCVD might result in a $-\mathrm{c}$ GaN film with a rough surface [21]

3. The dependence of various properties on the polarity was revealed [22] [23].

Claims 1 and 2 indicate the importance of the growth process, as discussed in Sec. 4, and claim 3 is related to the dependence of impurity adsorption on the polar surface, as discussed in Sec. 5

In order to extend the possibilities of techniques based on the TEM, efforts have been made continuously to observe atomic alignment with high-resolution image matching [24], to introduce micro-channeling effects during EDS analysis [25], to detect the N K-edge and Ga L-edge during EELS analysis [26], or to count dif- 
fracted electrons quantitatively [27]. The polarity can also be evaluated by these new approaches.

2.3.3 1997-1998: Surface reconstruction, chemical stability and CAICISS

There were two interesting reports in '97. One of these, which highlighted the temperature dependence of the surface reconstruction on the polarity, was carried out by Smith et al. [28]. Held et al. confirmed this surface reconstruction by RHEED observations of bulk GaN samples for which the polarity had been rigorously identified [29]. RHEED patterns that were characteristic of (1x1) and $(2 \times 2)$ reconstructions for $-\mathrm{c}$ and $+\mathrm{c}$ polar surfaces respectively were observed against the [11 $\overline{2} 0]$ azimuth under a constant supply of $\mathrm{NH}_{3}$ gas. The quality of the GaN samples needs to be sufficiently good to achieve these surface reconstructions. When the surface reconstructions were analyzed theoretically by taking into account the polarity and surface-termination atoms, the most favorable element to terminate the surface was evaluated as being $\mathrm{Ga}$, in spite of the polarity [30]. The relationship between the termination and the reconstruction are described in detail in an excellent review [31].

Another technique involves the chemical stability of the $-\mathrm{c}$ GaN surface in alkali solution [32]. Apparently, c GaN films are etched in $\mathrm{KOH}$ or $\mathrm{NaOH}$, while $+\mathrm{c} \mathrm{GaN}$ is inert to these solutions. The polarity that was determined by investigating the chemical stability was consistent with that determined by using hemisphericallyscanned x-ray photoelectron diffraction (HSXPD) [6]. We reported the mechanism for the selective etching, in that $\mathrm{OH}^{-}$in solution would promote etching, attacking one back-bond of the Ga that was bonded to the nitrogen on the $-\mathrm{c}$ polar surface [33]. The etching effects that originate from side facets or dislocations are still unknown, especially for GaN with rough surface morphology [34]. This chemical stability, however, is the easiest way to determine the polarity of $\mathrm{GaN}$

The methods mentioned above seem not to be suitable for determining the polarity of thin and poor quality GaN such as LT-buffer layers. In '98, we used CAICISS to determine their polarity [35]. The polarity of LT-GaN buffer layers was successfully evaluated for the first time by CAICISS [36]. This technique has been used for analyzing the polarity of MBE-GaN by Shimizu et al. [37]. The various features and advantages of CAICISS will be discussed in Sec. 2.4.

\subsubsection{Recent movements}

The other methods are briefly commented on according to the data in Table (b). The polarity can be determined by observation of both the angular dependence of the $\mathrm{Ga}$ K-edge [38] and the crystal truncation rod [39] generated by the standing wave of the x-rays from synchrotron radiation. Recently, a GaN film with both polarities was deposited by MBE on a single sapphire substrate [40]. The properties in the two regions were measured, and the relative differences in the polarity were observed. A1 (TO) mode appeared in Raman spectroscopy in the $-\mathrm{c} \mathrm{GaN}$ region [41] due to a higher level of impurities and defects (also discussed in Sec. 5.1). The surface potential detected by KPFM was $+25 \pm 19$, $30 \pm 10 \mathrm{meV}$ [42], and the surface charge $(\sigma / \mathrm{e})$ evaluated by PFM was $-1.78 \times 10^{13}, 1.83 \times 10^{13} \mathrm{~cm}^{-3}$ [43] for the $+\mathrm{c}$ and the $-\mathrm{c}$ GaN regions, respectively. These polarity dependences are important for device design with respect to the potential at the interface [44].

\subsection{Polarity characterization by CAICISS}

\subsubsection{Principle and advantages}

Figure 3 shows a schematic illustration of the CAICSS equipment that we used in this research. The $\mathrm{He}^{+}$beam is pulsed by chopping the aperture (150ns duration at $100 \mathrm{kHz}$ repetition rate) and is accelerated at low energy ( $2 \mathrm{keV}$ in this article). The He ion beam impinges on the sample surface with a $2 \mathrm{~mm} \phi$ spot-size, focused by an Einzel lens. The diameter of the shadow cone formed by the low energy ion beam is calculated to be several $\AA$, which is much larger than the figure of $0.1 \AA$ that is used for high energy ions [45], such as in Rutherford backscattering. The larger shadow cone enhances the crosssection of the scattering, and detection becomes very sensitive to atoms in the surface region. By changing the incident angle, both shadowing and focusing effects take place according to the atomic arrangement on surface, as illustrated in Figure 4. CAICISS is different from time-of-scattering and recoiling spectrometry (TOFSARS [46]), using the principle of elastic recoil detection.

According to the procedure in Ref. [5] as carried out by Katayama et al., we changed the incident angle $\alpha$ from $90^{\circ}$ (normal to sample) towards a lower angle. In CAICISS, $\mathrm{He}^{+}$and $\mathrm{He}^{0}$ (He particles) are back-scattered along an angle of $180^{\circ}$, due to impact collisions with atoms on the surface, and are detected by a multi channel plate. The intensity of the back-scattered He ions depends largely on the incident angle. Consequently, an angular dependence against an identical atom is obtained, as shown in Figure 4. The better the quality, the deeper the dip ((1) in Figure 4) and the narrower the width of the peak ((2)).

A specific feature of CAICISS is that it is a simple way of quantitatively analyzing the atomic arrangement on the surface, such as the distance and the angle made with neighboring atoms, because the analysis of the scattering orbitals can be extremely simplified by the focusing and shadowing effects and by taking only ions that have impact-collided with atoms into account. Using these features, the atomic structure of the surface 
(several nm deep) can be non-destructively analyzed in real space with CAICISS. The potential of CAICISS for determining the surface atomic arrangement in real space has been demonstrated for Si surfaces, compound semiconductors [47] [48] and oxide thin films [49].

The polarity can be determined by the positions of the parabolic shadowing dip and the focusing peak of the $\mathrm{He}^{+}$beam in CAICISS analysis. When the incident angle of a $\mathrm{He}^{+}$beam that is irradiated from the [11 20 ] azimuth is changed, the angular dependence of the cation signal intensity is represented by one or two peaks around $70^{\circ}$ for $+\mathrm{c}$ and $-\mathrm{c}$ polarity $\mathrm{GaN}$, respectively. These angular dependences can be calculated by computer simulation [50]. However, we have experimentally determined the polarity of a $\mathrm{GaN}$ film from the angular dependence measured by CAICISS, by comparing it to those shown in Figure 5 for bulk $\mathrm{ZnO}$ with $\mathrm{Zn}$ $(+c)$ and O- (-c) face polarity [51]. This was achieved without using the results of simulations. This is possible because $\mathrm{ZnO}$ has the same crystalline structure and very similar lattice constants to those of $\mathrm{GaN}$, since they are neighboring elements in the periodic table.

We have to comment here that it is not the termination atoms but the polarity, which can be analyzed by the CAICISS method that we use in this section. The competence of CAICISS for determining the polarity of III-nitride can be best demonstrated when it is applied to very thin films, such as LT-buffer layers and quantum well structures. When the CAICISS technique is to be used for thicker III-nitride samples, cross-checking should be implemented using either CBED or the chemical stability in alkali solution.

\subsubsection{Application of CAICISS to an InGaN SQW}

The types of atoms that the $\mathrm{He}^{+}$beam collides with can be distinguished by determining the TOF (calculated from the distance that the He has traveled), the acceleration voltage and from the weight of the atoms. Figure 6

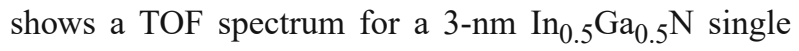
quantum well (SQW) on a GaN film at normal incidence to a He ion beam [52]. Since the length of travel and the energy of the $\mathrm{He}$ ions are $836 \mathrm{~mm}$ and $2 \mathrm{keV}$, respectively, the TOFs of the He that is backscattered due to collisions with the In and the Ga can be calculated theoretically to be $6417 \mathrm{~ns}$ and $6550 \mathrm{~ns}$, respectively. The position of the two sharp peaks in Figure 6 can thus be assigned to the In and Ga signals. TOF spectra with higher mass-resolution for cases where both atoms have atomic weights that are close to each other can be obtained by using $\mathrm{Ne}$ ions instead of $\mathrm{He}$ ions. The broader TOF spectrum after the Ga signal is attributed to the multiple scattering of He ions. Since the cross-section of light atoms such as nitrogen is smaller, their signals are detected after a longer time-of-flight, and are likely to be in the noise level in Figure 6. An In signal, which is barely detectable, for the 6-nm GaN capped SQW (as indicated in the inset) is probably derived from the interface between the SQW/GaN, due to the channeling effect at normal incidence. This In signal was hardly detectable at other incidence angles. This indicates that CAICISS analysis can detect information from the surface region of III-nitrides, down to a depth of several $\mathrm{nm}$.

The integrated signal for the III-group element (shadow area in Figure 4) from each TOF spectrum with changing angle of incidence was obtained to evaluate their polarity. Surface contaminants such as $\mathrm{C}$ and $\mathrm{O}$, which have small cross-sections, would not have any influence on determining the polarity. Figure 7 shows the angular dependence of the intensities of Ga and In in CAICISS-TOF spectra for an $\operatorname{In}_{0.5} \mathrm{Ga}_{0.5} \mathrm{~N}$ SQW. It was confirmed from comparison with the results in Figure 5 that the alloyed In has $+c$ polarity, while the variation in the $\mathrm{Ga}$ signal also indicates $+\mathrm{c}$ polarity. The indium atoms incorporated into the $\operatorname{In}_{\mathrm{x}} \mathrm{Ga}_{1-\mathrm{x}} \mathrm{N}$ SQW were found to occupy substitutional sites for $\mathrm{Ga}$, and they exhibited $+\mathrm{c}$ polarity.

\section{Management of polarity in MBE, PLD, and HVPE-GaN}

GaN films are deposited by a variety of growth techniques by different research groups. Reports claiming to show examples of polarity-control are surveyed for each growth technique in this section. Features that are incorporated to control the polarity of $\mathrm{GaN}$ are summarized for each of the common growth methods (MBE, PLD and HVPE) with respect to conditions used for treatment of the substrate and/or the LT-buffer layer.

\subsection{MBE}

Both nitridation of sapphire substrates and deposition under III-rich conditions are considered to be suitable techniques for obtaining high-quality GaN films by MBE. Table II (a)IIa and Table II (b)IIa show a list of research groups, each of which has their own accumulated know-how on growth strategies. Polarity control of MBE-GaN will now be reviewed, focusing on the conditions used for substrate treatment and on the buffer layer technologies that are shown in the Tables.

3.1.1 Conditions used for treatment of the sapphire and for the buffer layer

\section{auto Substrate nitridation}

Nitridation of the sapphire is carried out by almost all of the research groups. N-radicals generated by an rf plasma are conventionally used for this treatment, which takes place at temperatures ranging from 200 to $1000^{\circ} \mathrm{C}$. Sometimes $\mathrm{NH}_{3}$ gas can be used. 
Heinlein et al. systematically investigated the time dependence of the nitridation and concluded that it took $200 \mathrm{~min}$ of exposure to $\mathrm{N}$-radicals to complete the first monolayer of the surface nitride in an MBE chamber [53]. The nitridation done by Mikroulis et al. (Univ. of Crete) at $200^{\circ} \mathrm{C}$ caused an improvement in the flatness of the sapphire surface and increased the in-plane lattice constant, typically by a value of approximately $9 \%$. The surface become rougher and the lattice constant could be increased by $6.2-6.8 \%$ by nitridation at $750^{\circ} \mathrm{C}$ [54]. Namkoong et al. (Georgia Inst. of Tech.) confirmed that $6 \AA$ of AlN and $23 \AA$ of $\mathrm{AlN}+\mathrm{NO}$ were formed by nitridation at $200^{\circ} \mathrm{C}$ and $700^{\circ} \mathrm{C}$, respectively [55]. N-radicals are so reactive that they can even nitride the surface of a sapphire substrate at a temperature as low as $200^{\circ} \mathrm{C}$. This is completely different from nitridation caused by a flow of $\mathrm{NH}_{3}$ gas, as used in MOCVD (refer to Sec. 4.2). In a technique that is analogous to nitridation in MOCVD, a flow of $\mathrm{NH}_{3}$ gas was introduced into the MBE process by Sonoda et al. (AIST) [56] and Held et al. (Univ. of Minnesota) [29]. Although the two groups published no results of this surface nitridation technique, Grandjean et al. pointed out that AlN could also be formed by nitridation using an $\mathrm{NH}_{3}$ flow at $850^{\circ} \mathrm{C}$ for $10 \mathrm{~min}$ [57].

The polarity of the AlN formed by the nitridation process was suggested to be $-\mathrm{c}$ polarity from theoretical calculations done by Felice et al. [58] (discussed in Sec. 3.1.4). Indeed, it was reported that initial nitridation of the sapphire substrate favors the growth of GaN films along the $-\mathrm{c}$ direction [59].

\section{auto Conditions used for AIN and GaN buffer layers}

The polarities of GaN films on non-nitrided sapphire substrates deposited by Dimitrov et al. (Walter Schottky Inst.) using GaN or AlN buffer layers with the same thickness of $15 \mathrm{~nm}$ were identified as $-\mathrm{c}$ or $+\mathrm{c}$, respectively [60]. In cases such as Piquette et al. (Cal. Inst of Tech. [61]) and Namkoong et al. (Georgia Inst. of Tech. [62]) as well as the work of Sonoda et al. (AIST [59]), MBE-GaN films on nitrided substrate seem to be able to be categorized as $+\mathrm{c}$ and $-\mathrm{c}$ polarity on $\mathrm{AlN}$ and $\mathrm{GaN}$ buffer layers, respectively. The polarity seems to be determined by the choice of buffer layer. However, a dependence on the growth conditions has sometimes been observed for both AlN and GaN buffer layers.

The polarity could be systematically varied by changing the thickness of the AlN buffer layer. Dimitorov et al. (Cornell Univ.) demonstrated that the polarity could be controlled from $-\mathrm{c}$ to $+\mathrm{c}$ polarity (through mixed polarity layers) by using buffer layers corresponding to $0 \mathrm{~nm},<5 \mathrm{~nm}$, and $5-15 \mathrm{~nm}$ of AIN [60]. GaN films on thinner AlN buffer layers $(<12 \mathrm{~nm})$ are likely to contain IDs, as reported by Georgia Inst. of Tech. [55].
When GaN films are grown not only on sapphire, but also on GaAs (111) B-face substrates, $+c$ polarity can be realized by increasing the thickness of the AlN buffer layer $(>20 \mathrm{~nm})$ [63]. Furthermore, the growth temperature of the AlN buffer layer seems to be important. AlN buffer layers deposited at temperatures higher than those used for depositing HT-GaN layers tend to result in $+\mathrm{c}$ polarity, as observed in Georgia Inst. of Tech., the Walter Schottky Inst. and at the Univ. of Minnesota, while the AIST group claim that lower temperatures are more suitable.

Thicker GaN buffer layers lead to $+c$ polarity for MBE-GaN, as reported by Huang et al. Increasing the growth rate of the $\mathrm{GaN}$ (increase in the amount of $\mathrm{Ga}$ [64]) also seems to be effective (Virginia Commonwealth Univ.) [65]. GaN buffer layers were deposited on $\mathrm{NH}_{3}$-nitrided sapphire by AIST [56] and Univ. of Minnesota [29]. The polarities determined by the two groups were opposite (the former $-\mathrm{c}$, and the latter $+\mathrm{c}$ ). In addition, the polarity of MBE-GaN was converted from $+\mathrm{c}$ to $-\mathrm{c}$ by annealing the GaN buffer layer, as was observed in Univ. of Crete [54]. Therefore, the conflict in the use of a GaN buffer layer in MBE was still apparent.

It was very difficult from these papers to find both general conditions that completely covered all of the research groups and any clear relationship between the polarity and the growth conditions. However, we consider through reading many reports that $+\mathrm{c}$ GaN would be obtained on an AlN buffer layer deposited under IIIrich (higher growth rate) conditions at high temperature in MBE.

auto Insertion of a metal layer

$\mathrm{Xu}$ et al. (Chiba Univ.) observed polarity conversion by inserting several $\mathrm{Al}$ metal layers onto a $-\mathrm{c}$ GaN film after $100 \mathrm{~nm}$ of deposition in MBE [66]. A bi-layer of Al metal was explained as the cause of the converted polarity, and this technique has now been applied to the MOCVD process [67]. Park et al. ((Dongguk Univ.) deposited an $\mathrm{Al}$ metal layer directly onto a nitrided sapphire substrate and successfully obtained $+\mathrm{c}$ GaN [68]. Kikuchi et al. (Sophia Univ.) introduced high temperature-grown AlN multiple intermediate layers (HT-AlNMIL) in migration enhanced epitaxy (MEE), in which $\mathrm{Al}$ and $\mathrm{N}$ are alternatively supplied into the MBE chamber [69]. They controlled the polarity by changing either the number of pairs of HT-AIN-MIL and GaN spacers or the thickness. Yoshida (Furukawa Co. Ltd.) verified the potential of the insertion of Ga metal [70] [71]. Similarly, GaN films can be achieved using a hot wall epitaxy, which consists of the low temperature deposition of Ga metal and subsequent nitridation [72]. In addition, we found that $\mathrm{M}$-face GaN could be grown on 
an Al layer deposited on a sapphire substrate and subsequently nitrided in our MOCVD reactor [73]. Thus, the deposition of a metal layer onto an interface is highly advantageous for controlling orientation, including the polarity of GaN film growth.

\subsubsection{Mg accumulation layer}

Ramachandran et al. have investigated the phenomenon of $\mathrm{Mg}$ adsorption on the surface of a $+\mathrm{c}$ GaN layer grown on $\mathrm{Si}$-face $6 \mathrm{H}-\mathrm{SiC}$ by PAMBE. When the film was exposed to $1.2 \pm 0.4 \mathrm{ML}$ or more of $\mathrm{Mg}$ during growth under Ga-poor conditions, they found that the polarity for the subsequent GaN film switched to $-\mathrm{c}$ polarity [74]. When the inversion takes place, the incorporated $\mathrm{Mg}$ concentration in the layer was confirmed to be approximately $8 \times 10^{19} \mathrm{~cm}^{-3}$. At the point where the polarity changed, the interface was rough, with a zigzag inversion domain boundary with mainly $\{1113\}$ facets and a few (0001) segments [75]. Recently, Grandjean et al. have controlled the polarity conversion, not only from $+\mathrm{c}$ to $-\mathrm{c}$, but also from $-\mathrm{c}$ to $+\mathrm{c}$ polarity in $\mathrm{NH}_{3}-$ MBE [76]. The interface in the latter conversion was confirmed as being flat.

A monolayer of $\mathrm{Mg}$ deposits on the Ga-terminated surface of the $+c \mathrm{GaN}$ film. Since the local structure of the $\mathrm{Mg}_{3} \mathrm{~N}_{2}$ is more favorable than that of the bulk GaN, the $\mathrm{Mg}$ is likely to bond with the $\mathrm{N}$ atoms. Consequently, the displacement of the Ga and the $\mathrm{N}$ atoms in the outermost layer should occur, forming the configuration $M g-N-G a / G a-N$ from $M g-G a-N-G a-N$ on the $+\mathrm{c}$ polar surface. The sign $G a / G a$ indicates IDB, consisting of a plane of Ga-Ga bonds. The $\mathrm{N}$ atoms are six-fold coordinated with the outermost $\mathrm{Mg}$ and the underlying $\mathrm{Ga}$. This surface structure has been theoretically calculated to be the most stable [31] [74]. Recently, a model of pyramidal (zigzag) inversion domains originating from the $\mathrm{Mg}$ on the (0001) segment of the boundary was theoretically performed by first-principles pseudopotential density functional calculations [77]. The most favorable structure of the $\mathrm{Mg}$ boundary inserted into the GaN was evaluated as abcab stacking across the (0001) segment, corresponding to the atomic sequence $\mathrm{GaN}$ $M g N G a$, where the side of the boundary lies along the $\{1113\}$ direction, corresponding to the zigzag inversion domain boundary. In this structure, the concentration of $\mathrm{Mg}$ in the boundary layer was calculated to be $3 / 4$ monolayer, occupying $\mathrm{H} 3$ sites.

\subsubsection{Deposition of GaN film: V/III ratio and growth rate}

Tarsa et al. deposited GaN films homo-epitaxially on $+\mathrm{c}$ GaN templates by plasma-assisted MBE [78]. GaN films deposited with a low V/III ratio (Ga-stable) had a quality comparable with the underlying GaN template, while GaN films with a high V/III ratio (N-stable) showed a faceted surface and poor crystalline quality.
Held et al. [79] and Myers et al. [80] deposited on -c $\mathrm{GaN}$ templates by MBE. The former obtained GaN films with 3-D growth under excess $\mathrm{NH}_{3}$ (Ga-limited growth) and films with a step-flow growth under excess $\mathrm{Ga}\left(\mathrm{NH}_{3}\right.$-limited growth). The latter obtained GaN samples with pyramidal hillocks or a flat surface morphology under N- and Ga-stable conditions, respectively. The Ga-rich condition is likely to result in GaN films with a smooth surface, regardless of the polarity of the template.

The dependence of the polarity on growth rate is also observed for GaN and AlN buffer layers, shown in Table (a), as well as in $\mathrm{ZnO}$ films with the same wurtzite crystal structure [81]. Takahashi et al. deposited GaN films on GaAs (111) A and B-face substrates by MOMBE. The deposition was carried out at $700^{\circ} \mathrm{C}$ by changing the Ga flux (beam equivalent pressure (BEP); 2 8x10${ }^{8}$ Torr) under a constant supply of DMHy as the $\mathrm{N}$ source. The growth rate of the GaN on both substrates increased up to $5 \times 10^{-8}$ Torr of Ga supply, and then saturated at $400 \mathrm{~nm} / \mathrm{h}$ above that level. This indicates that the growth was promoted with a supply-limit (N-rich) for the lower BEP, while it occurred with a surface kinetic limit (Ga-rich) for the higher BEP. GaN films on A-face GaAs (111) were found to have $+\mathrm{c}$ polarity, and were independent of the growth rate. On the other hand, the polarity on the GaAs (111) B-face was -c for the supply-limited condition, and it was $+\mathrm{c}$ when it was kineticlimited. GaN grown under III-rich conditions (kinetic limited, Ga- stable or limited growth) is considered to predominantly display $+c$ polarity [82].

3.1.4 Factors for controlling the polarity in MBE-GaN on sapphire substrate

The following are considered to be the key points that are decisive in determining the polarity of MBE-GaN;

1. Use of an AlN buffer layer deposited on a sapphire substrate at higher temperature with a higher growth rate (III-rich conditions)

2. Insertion of an $\mathrm{Mg}, \mathrm{Al}$ and $\mathrm{Ga}$ metal layer at the interface

3. Use of a thicker LT-GaN buffer layer.

The vapor pressure of $\mathrm{GaN}$ is much higher than that of AlN, as shown in Figure 8 [83]. AlN buffer layers, with their lower vapor pressure, should be suitable to act as nucleation layers for MBE-GaN grown under high vacuum conditions. Felice et al. calculated theoretically the atomic structure of films consisting of approximately 1 bilayer of AIN on c-plane sapphire substrates [58]. Under equilibrium conditions, the Al layer in the $\mathrm{H} 3$ sites lying between the last $\mathrm{O}$ plane (blue region) and the first $\mathrm{N}$ plane (yellow region) maintain the stoichiometry of bulk sapphire for $2 / 3$ monolayers, as 
shown in Figure 9 (a) and Figure 9(b). This favorable structure could be changed by the amount of $\mathrm{Al}$ in the initial growth, from Al-rich in Figure 9 (a) to Al-poor in Figure 9 (b). Both of the geometries of the AlN on the outermost layer (between the green brackets) corresponded to $+\mathrm{c}$ polarities (from previous calculations) [84]. In contrast, the alignment of the AIN (between the red brackets) in Figure 9(c) and Figure 9(d) corresponded to $-\mathrm{c}$ polarity. This structural difference is observed in the complete interface of $\mathrm{Al}$ adatoms lying in the $\mathrm{T} 4$ sites between the last $\mathrm{O}$ plane and the $\mathrm{N}$ plane. The calculations predicted that the polarity of these very thin films on sapphire substrates would be attributed to that of the III-V nitrides. Moreover, since the two structures in Figure 9 (b) and Figure 9 (c) have very similar formation energies, independent of $\mathrm{Al}$ abundance, it is assumed that a slight fluctuation in conditions in the initial stages of deposition can alternately switch the structure. The situation that is shown in Figure 9 (c) must occur under non-equilibrium conditions, such as nitridation of the sapphire under Al-deficient conditions. Consequently, the nitridation of sapphire is regarded as resulting in $-\mathrm{c} \mathrm{GaN}$, though moderate nitridation as carried out by the AIST group [56] might form the interface structure shown in Figure 9 (b). Increasing the supply of group III implies that the growth of nitride materials would approach the equilibrium state, forming the structures with $+c$ polarity shown in Figure 9 (a) and Figure 9 (b).

\subsection{PLD}

In the pulsed laser deposition (PLD) technique, IIInitride films are fabricated in an $\mathrm{N}_{2}$ ambient through the deposition of precursors that are ablated from a metal target or from nitride powder by an intense pulsed excimer or Nd:YAG laser. Since the use of PLD makes it possible to lower the substrate temperature, various substrates can be used in PLD [85] [86].

The orientation of GaN films deposited by PLD was $\mathrm{GaN}[11 \overline{2} 0] / / \mathrm{Al}_{2} \mathrm{O}_{3}[1 \overline{1} 00]$, which is similar to that in the cases of MOCVD and MBE. Ohta and Zhou et al. reported that $-\mathrm{c} \mathrm{GaN}$ was obtained by PLD when deposition occurred directly onto a sapphire substrate without any buffer layer. By introducing 19nm of AlN [87] or $10 \mathrm{~nm}$ of $\mathrm{Al}_{0.8} \mathrm{Ga}_{0.2} \mathrm{~N}$ [88] (as employed by the former and the latter, respectively) the films were reported to be converted to $+c$ polarity. Furthermore, an AlN buffer layer deposited under Al-rich conditions made the GaN film grow along the $+\mathrm{c}$ polar direction, and the initial growth on the sapphire substrate was decisive in determining the polarity [89]. GaN grown on a $\mathrm{Si}$-face $6 \mathrm{H}-\mathrm{SiC}$ substrate had $+\mathrm{c}$ polarity. Betterquality GaN films were obtained under Ga-rich conditions [90]. Thus, the trends for GaN films deposited by
PLD seem to be similar to those deposited by MBE, as mentioned in Sec. 3.1.

\subsection{HVPE}

HVPE has mainly been used in order to fabricate bulk or free-standing $\mathrm{GaN}$ with lower threading dislocations on MOCVD-GaN templates patterned with $\mathrm{SiO}_{2}$ [91] or W [92] masks. Smooth HVPE-GaN was obtained by the insertion of a $\mathrm{ZnO}$ layer on a sapphire substrate. This $\mathrm{GaN}$ was confirmed to be $+\mathrm{c}$ polarity, as demonstrated by Romano et al. [20] in Sec. 2.1. The initial growth on the substrate seems to be also important in HVPE. In this section, the conditions for HVPE-GaN deposition on substrates without a GaN template are summarized in terms of surface morphology (polarity), as in Sec. 3.1 for MBE.

\subsubsection{Until 1992: Direct growth, $\mathrm{GaCl}$ treatment, and $\mathrm{ZnO}$ insertion}

The first GaN film was deposited on a sapphire substrate by HVPE in '69 [93]. Judging from its hexagonal-facetted surface morphology, this GaN film had -c polarity. Intensive efforts have been made to grow smooth large area HVPE-GaN films directly on sapphire substrates by Monemar et al. [94].

In Table III, reports of $\mathrm{GaN}$ growth on sapphire substrates by HVPE are listed with respect to the relationship between initial growth conditions and surface morphology. The first smooth HVPE-GaN was achieved by Naniwae et al. in 1990 [95]. The key technology was the treatment of the sapphire substrate by $\mathrm{Ga}+\mathrm{HCl}$ at $1030^{\circ} \mathrm{C}$. In order to obtain smooth $\mathrm{GaN}, \mathrm{Ga}+\mathrm{HCl}$ treatment should be carried out for more than $20 \mathrm{~min}$, as shown in the Table. Two years later, Detchprochm et al. found that the insertion of a $\mathrm{ZnO}$ layer on the sapphire substrate made it possible to grow HVPE-GaN that was transparent, with a smooth surface [96]. A 10-300nm thick $\mathrm{ZnO}$ buffer layer was deposited on the sapphire substrate by sputtering at room temperature, and then the sapphire substrate that was covered with the $\mathrm{ZnO}$ layer was introduced into the HVPE system.

The vapor pressure of $\mathrm{ZnO}$ is so high at $1000^{\circ} \mathrm{C}$ in an HVPE reactor that there was no evidence of $\mathrm{ZnO}$ at the GaN/sapphire interface, as reported by Molnar et al. [97]. Ga atoms left on the sapphire by the $\mathrm{GaCl}$ treatment should be desorbed as well. However, it is supposed that a very small fraction of the $\mathrm{Zn}$ or the Ga could form compositions that would play a role in converting the polarity at the interface of the sapphire.

\subsubsection{7-1999: AIN and GaN buffer layers}

AlN and GaN buffer layers began to be used in 1997. The effectiveness of AlN buffer layers was confirmed by Lee et al. for the first time [98]. Paskova et al. made a comparison of the effects of sapphire nitridation, $\mathrm{GaCl}$ treatment and AlN buffer layers for HVPE-GaN growth 
[99]. (The growth of AlN buffer layers was carried out by sputtering in a separate apparatus due to the $\mathrm{AlCl}_{3}$ corroding the quartz tube of the HVPE reactor). It was concluded that the smoothest GaN was achieved by the use of an AlN buffer layer.

Wagner et al. reported that HVPE-GaN grown on a $\mathrm{GaN}$ buffer layer was smoother than that on an AlN buffer layer deposited by MOCVD [100]. Here, it is worth noting that HVPE-GaN on an LT-GaN buffer layer less than $10 \mathrm{~nm}$ thick had a hexagonal-facetted surface (discussed in Sec. 4.3 Recipe 1-(2)). The GaN buffer layer could be desorbed during the ramping of the substrate temperature under an $\mathrm{NH}_{3}$ ambient, and then the unintentional direct-growth of HVPE-GaN on the sapphire substrate was supposed to take place. In contrast, smooth HVPE-GaN was deposited on AlN buffer layers. This is why AlN buffer layers, which have a lower desorption rate (as shown in Figure 8) were expected to work as nucleation layers even at the high temperatures used for HVPE-GaN growth.

The importance of variations in the LT-buffer layer caused by annealing can be found in the report by Tavernier et al., who applied a similar buffer layer technology to that used in MOCVD to HVPE in a single chamber [101]. Their studies of buffer layers revealed that layer thickness and annealing conditions are crucial to obtaining HVPE-GaN of high quality.

\subsubsection{0-2003: Kinetic effect and a new approach}

Small islands that were typically several $\mathrm{nm}$ in height were formed on sapphire substrates by the nitridation treatments used in HVPE [102] and in MOCVD. Nitridation of the substrate is likely to result in $-\mathrm{c} \mathrm{GaN}$ growth with hexagonal-facetted surfaces, as discussed in the section on MBE-GaN. However, such a trend is not observed in HVPE-GaN. Namerikawa et al. reported that $+\mathrm{c}$ polarity was observed for HVPE-GaN samples deposited on both A- and B- face GaAs (111) substrates [103]. This is probably due to the use of growth rates as high as a few $\mu \mathrm{m} / \mathrm{min}$. (Murakami et al. found that when an LT-GaN buffer layer on a B-face substrate was annealed in an $\mathrm{NH}_{3}$ ambient, the substrate was deteriorated due to etching of the buffer layer, suggesting that GaAs (111) B-face substrates are not suitable for $\mathrm{GaN}$ deposition [104].)

In HVPE-GaN, the coalescence of the GaN islands occurs rapidly (within $10 \mathrm{sec}$ of their growth) corresponding to $0.4-0.5 \mu \mathrm{m}$ of film thickness [105]. The quality of the HVPE-GaN can be divided into two regimes, thinner than $0.4-0.5 \mu \mathrm{m}$ and thicker than that, which correspond to destructive and better quality, respectively. Gu et al. obtained better quality HVPE$\mathrm{GaN}$ by changing the optimum conditions for the two regions [102]. In addition, in a similar way to the case of MEE [69] given in Sec. 3.1, flow modulated growth (FMG) with a periodically interrupted $\mathrm{HCl}$ flow under a constant flow of $\mathrm{NH}_{3}$ can also improve HVPE-GaN, as reported by Zhang et al. [106].

\subsubsection{Features for controlling polarity in HVPE-GaN}

Nitridation of the sapphire substrates in HVPE does not have a great influence on the surface morphology (polarity) of the GaN, probably due to the high growth rate induced by the kinetic effect. However, the interface compositions between the substrate and the initial very thin film are crucial to $+c$ polarity, as provided in the following:

1. $\mathrm{GaCl}$ treatment of the sapphire substrate

2. Deposition of $\mathrm{ZnO}$ and AlN layers in an isolated system

3. Use of a thicker LT-GaN buffer layer.

These features are supposed to be essentially equal to those used in MBE. In order to understand the general context of polarity control beyond these growth techniques, it will be necessary to be able to analyze a sapphire surface treated with $\mathrm{GaCl}$ and also these buffer layers.

\section{Polarity management in MOCVD-GaN}

An LT-buffer layer is indispensable, not only for growing high-quality HT-GaN films, but also for controlling their polarity, as observed in the drastic improvements in surface morphology that have been achieved since 1986 . The quality of the LT-buffer layer strongly depends on the substrate treatment, the growth conditions and the subsequent annealing. The dependencies of the LTbuffer layer on these conditions are highlighted by our studies (detailed below) under Articles, where we attempt to understand the implications of the various conditions. In the subsequent sections, entitled The Recipes, we propose methods that would lead to control of the polarity.

\subsection{Previous work}

A few years after the development of AlN and GaN buffer layers, LEDs based on III-nitride materials were realized by the MOCVD process. Device development has always been more advanced in research into MOCVD-GaN. Therefore, know-how for improving $\mathrm{GaN}$ materials has not always been reported as often as it might have been. As far as we could determine during our survey, the number of reports claiming polarity-control in MOCVD-GaN are far fewer than those for MBE$\mathrm{GaN}$. Polarity issues in MOCVD-GaN seem to have been left behind. There are, however, some reports that detail how the optimization of the growth conditions for each of the processes in MOCVD happened to result in changes in the polarity and/or the surface morphology. 
The first GaN films deposited by MOCVD in 1984 had hexagonal-facetted [107] or granular surfaces [108]. By using an LT-AlN buffer layer, GaN with a smooth surface was achieved for the first time in 1986 [1]. It has been thought that this variation could be related to the polarity. Hwang et al. investigated the influence of sapphire nitridation on GaN films in 1995 [109]. Their nitridation was carried out at $900^{\circ} \mathrm{C}$ for $5 \mathrm{~min}$. GaN films using $50 \mathrm{~nm}$ of LT-GaN buffer layer deposited on nitrided and non-nitrided sapphire substrates had hexagonal-facetted or smooth surfaces, respectively. The carrier density for GaN films on nitrided sapphire was higher by one order of magnitude than that for films on non-nitrided substrates. In addition, the mobility of the former was $1 / 4$ of that of the latter. That is, the substrate nitridation not only had an influence on the surface morphology, but also on the properties of the GaN. Van Der Stricht et al. systematically changed the surface morphology of GaN films deposited on nitrided sapphire substrates from hexagonal-facetted to smooth by lowering the deposition temperature of the $\mathrm{GaN}$ buffer layer from 550 to $450^{\circ} \mathrm{C}$ [110]. The variations (re-crystallization or sublimation [111] [112]) of the LT-buffer layer induced by the gas ambient [113] and the annealing time [114] [115] were investigated intensively to improve the quality of $\mathrm{GaN}$ films. Thus, the key technologies for controlling the polarity in MOCVD can usually be found in thesis reports. The implications of these conditions will be discussed with respect to polarity-control in the subsequent sections.

\subsection{Our sample conditions in MOCVD}

Our GaN films have been grown conventionally on cplane sapphire substrates using LT-buffer layers by a two-step sequence in an atmospheric pressure MOCVD apparatus with a vertical water-cooled quartz reactor. Trimethyl-gallium (TMG), trimethyl-aluminum (TMA) and $\mathrm{NH}_{3}$ gases were used as the $\mathrm{Ga}, \mathrm{Al}$ and $\mathrm{N}$ source materials, respectively. $\mathrm{H}_{2}$ and $\mathrm{N}_{2}$ were used as the carrier gases. A quartz inner tube was used in order to enhance the flow velocity of the source gases arriving on the substrate on a graphite susceptor. The MOCVD process involves the following steps; substrate treatment [cleaning in flowing $\mathrm{H}_{2}$ at $1000^{\circ} \mathrm{C}$ and/or nitridation], deposition of an LT-buffer layer, ramping up the substrate temperature (annealing of the buffer layer) and deposition of the high-temperature (HT) GaN film. LT$\mathrm{GaN}$ or AlN buffer layers were used in our studies. Table summarizes the typical growth conditions.

Although the conditions can be independently controlled during each process step, each step has an influence on the subsequent processes. There are infinite combinations of conditions until deposition of the HT-
GaN film. The polarities of samples prepared under a representative condition for each process were analyzed by each of CAICISS, X-TEM and chemical stability.

\subsection{Substrate treatment and GaN buffer layer}

\subsubsection{Article 1: Surface of the treated sapphire substrate}

It is most important to recognize that the surface of the substrate is the first hetero-interface in GaN film growth. The surface of the sapphire substrate was investigated using XPS when the substrate was treated by cleaning under $\mathrm{H}_{2}$ or by nitridation under flowing $\mathrm{NH}_{3}$.

Although the surface of the sapphire substrate was sometimes covered with undesirable contamination $(\mathrm{Ga}$, $\mathrm{N}, \mathrm{Al}, \mathrm{Si}$ etc.) due to hysteresis in the MOCVD apparatus [116], oxygen was conventionally removed from the sapphire surface during $\mathrm{H}_{2}$ cleaning. Consequently, the surface was slightly rougher, and an Al-rich surface was formed, which was confirmed to be $\mathrm{Al}: \mathrm{O}=50: 50 \%$ by XPS. When it was subsequently nitrided under flowing $\mathrm{NH}_{3}$ at various temperatures between $600^{\circ} \mathrm{C}$ and $1080^{\circ} \mathrm{C}$, the surface compositions of the $\mathrm{Al}, \mathrm{O}$ and $\mathrm{N}$ were changed, as shown in Fig. 10. Nitrogen was detected for sapphire nitrided at even $600^{\circ} \mathrm{C}$, and the nitrogen composition increased with higher temperature, while the oxygen decreased.

Thus, an Al-rich surface was formed on the sapphire substrate by the removal of oxygen during $\mathrm{H}_{2}$ cleaning. In contrast, $\mathrm{AlO}_{\mathrm{x}} \mathrm{N}_{1-\mathrm{x}}$ was induced by nitridation, depending on the temperature used. These chemical states at the surface of the substrate play a decisive role in the polar structure of the buffer layer and also the evaporation behavior. (Refer to Recipes 1 and 2).

\subsubsection{Article 2: Structure of the LT-GaN buffer layer on} the nitrided sapphire substrate

To understand the correlation between the MOCVDprocess and the polarity, it is necessary to evaluate the polarity of the LT-buffer layer itself. Figure 11 shows CAICISS results for LT-GaN buffer layers on $\mathrm{H}_{2}$ cleaned and nitrided sapphire substrates [36] [117]. The dependence of the intensity on the incident angle shows less variation due to the poor crystalline quality of the buffer layer (refer to Sec. 2.4). However, the dominant polarity of buffer layers as thin as $20 \mathrm{~nm}$ can be judged from these results by comparison with the results in Figure 5. There are two interesting features observed from this result. Firstly, both as-deposited buffer layers show $+c$ polarity, independent of the substrate treatment. The other is that the resulting polarity for the layer on the nitrided sapphire was converted to $-\mathrm{c}$ polarity after the annealing, while the polarity was $+\mathrm{c}$ for the film on the $\mathrm{H}_{2}$ cleaned substrate. 
Our concern was focused on buffer layers on nitrided sapphire. The non-stoichiometric $\mathrm{AlO}_{\mathrm{x}} \mathrm{N}_{1-\mathrm{x}}$ layer formed by the nitridation is likely to have $-\mathrm{c}$ polarity, as indicated by theoretical calculations [58]. Both $+c$ and $-c$ polarity nucleate simultaneously on the nitrided sapphire, probably due to either inhomogeneous nitridation [117] or favorable formation energy. The surface of the as-deposited buffer layer would be covered with $a+c$ layer with higher growth rate [118]. Subsequent annealing of the film would make the $-\mathrm{c}$ domains rise to the surface due to the sublimation of the film. Based on these considerations, buffer layers on nitrided sapphire substrate are assumed to be covered with $\mathrm{a}+\mathrm{c}$ layer grown laterally over the $-\mathrm{c}$ domains.

To confirm this assumption, thicker buffer layers $(210 \mathrm{~nm})$ were prepared on nitrided sapphire and annealed for various times at $1040^{\circ} \mathrm{C}$. An LT-GaN buffer layer on a nitrided substrate was found to evaporate with a layer-by-layer mode due to the $\mathrm{AlO}_{\mathrm{x}} \mathrm{N}_{1-\mathrm{x}}$ on its surface [119]. Figure 12 shows the angular dependence of the Ga signal intensity in CAICISS for the thicker buffer layer annealed for $0,10,20$ and 30min [120]. The CAICISS result for the as-deposited sample shows predominantly $+c$ polarity [Figure 12 (a)]. The sample continues to have $+\mathrm{c}$ polarity after annealing for $10 \mathrm{~min}$. Sharpening of the peaks is also observed in the result, suggesting an improvement in the crystal quality near the surface [Figure 12 (b)]. The peak at $72^{\circ}$ splits into two peaks and the peak at $35^{\circ}$ intensifies with further annealing, as shown in Figs. 12 (c) and (d). This indicates that the film surface is transforming from $+\mathrm{c}$ polarity (triangles) to $-\mathrm{c}$ polarity (squares). The lines in Figs. 12 (c) and (d) present the weight ratio of $+\mathrm{c}$ : -c polarity at 5:5 and 2:8, respectively, with the assumption that they share the same crystal quality (i.e., the same intensity of the CAICISSS signal for $+c$ and $-c$ domains).

Since CAICISS analysis detects the atomic arrangement of only the surface region (as discussed in Sec. 2.4), the films were further investigated by TEM [120]. Figure 13 shows X-TEM images for the same samples that are shown in Figs. 12 (c) and 12 (d). Columnar IDs were found to extend to the surface, and dome-shaped domains were found near the interface, similar to the observations reported by Wu et al. [121]. With increasing annealing time (sublimation of the film), the domeshaped domains are exposed to the surface. The TEM images are consistent with the CAICISS spectra. Since the $-\mathrm{c}$ signal component of the CAICISS result increased after annealing, the inverted domains (dome shaped) can be considered to have $-\mathrm{c}$ polarity.

\subsubsection{Article 3: Interface between the GaN buffer and}

the treated sapphire substrate

The interface between the GaN buffer layer and the substrate was investigated by XPS. Figure 14 shows the annealing-time dependence of the peak position of N1s for buffer layers on both $\mathrm{H}_{2}$ cleaned and nitrided sapphire substrates. The peak positions for both as-deposited layers are observed at around $397.4 \mathrm{eV}$, corresponding to GaN. The sample on nitrided substrate mostly evaporated after annealing for $20 \mathrm{~min}$, because the position of $\mathrm{N} 1 \mathrm{~s}$ at $396.5 \mathrm{eV}$, corresponding to the AlN and Ga signals, was in the noise level. In contrast, $\mathrm{Al}_{\mathrm{x}} \mathrm{Ga}_{1-\mathrm{x}} \mathrm{N}$ was formed at the interface between the GaN buffer layer and the $\mathrm{H}_{2}$ cleaned sapphire substrate. The peak position for the annealed buffer layer on the $\mathrm{H}_{2}$ cleaned sapphire stayed at $396.8 \mathrm{eV}$, regardless of the time, and the Ga 3d peak was shifted to slightly lower binding energy from $\mathrm{GaN}(19.8 \mathrm{eV})$ [119].

Recently, we have deposited a GaN film by MOCVD on an $\mathrm{H}_{2}$ cleaned sapphire substrate that had once been exposed to air. Although the surface should have been terminated with oxygen, a $+c \mathrm{GaN}$ film with sufficient quality was obtained on the sapphire by two-step MOCVD without the need for a second $\mathrm{H}_{2}$ cleaning process [122]. The sapphire surface becomes rougher by $\mathrm{H}_{2}$ cleaning, represented by the weak RHEED pattern. In addition, a comparable GaN film with high quality was even grown on a sapphire substrate cleaned in an $\mathrm{N}_{2}$ ambient at more than $1000^{\circ} \mathrm{C}$ [123]. It is supposed from these facts that the thermal roughening of sapphire at higher temperature might be important as a nucleation site for the growth of the LT-buffer layer.

\subsubsection{Recipe 1: Thickness and annealing of the GaN} buffer layer on nitrided substrates

Taking into account the IDs structure of the GaN buffer layer on the nitrided sapphire reported in Article 2, we demonstrate how to control the polarity of the HT-GaN by changing the thickness of the buffer layers and the conditions used for the annealing. The mixed polarity of the buffer layers grown by MBE on nitrided sapphire has also been observed by CAICISS analysis [59]. Since GaN film growth on nitrided sapphire substrates is supposed to be similar to growth by MBE, our recipes in MOCVD will be compared with the features found in MBE, which are listed in Table (a) and Table (b).

auto Thickness

Thicker buffer layers $(160 \mathrm{~nm})$ were deposited and annealed for various times at $1040^{\circ} \mathrm{C}$ under a gas ambient of $\mathrm{NH}_{3}: \mathrm{H}_{2}: \mathrm{N}_{2}=750: 750: 500 \mathrm{sccm}$. The absorbance at $3.6 \mathrm{eV}$ decreases as a function of the annealing time, as shown Figure 15 (a), indicating a reduction in the thickness. Their polarities, as determined by CAICISS, are indicated in the figure. $\mathrm{GaN}$ films were deposited on 
these annealed buffer layers, with their polarities clearly identified. GaN films with smooth $(+\mathrm{c})$ and hexagonal faceted (-c) surfaces were confirmed when deposited on thicker buffer layers annealed for $10 \mathrm{~min}(+\mathrm{c})$ and more than $30 \mathrm{~min}(-\mathrm{c})$, respectively. The size of the hexagonal facets could be systematically changed up to $60 \mu \mathrm{m}$ by varying the annealing time of the buffer layer, as shown in Figure 15 (b). We suppose that the milky surface of the GaN film was probably due to $+\mathrm{c}$ and $-\mathrm{c}$ mixed growth [36].

The effect of the thickness of the buffer layer can be seen in the data for MBE-GaN films shown in Table (a). In spite of the presence of an AlN or GaN buffer layer, MBE-GaN films on thicker buffer layers are likely to have $+c$ polarity. When the group at Georgia Inst. of Tech. [62] increased the thickness of the AlN from 12 $\mathrm{nm}$ to $30 \mathrm{~nm}$, the polarity was converted from mixed polarity to $+c$ polarity. Similar results were obtained by both the Virginia Commonwealth University, who used $\mathrm{GaN}$ buffer layers more than $60 \mathrm{~nm}$ thick [65] and the Walter Schottky Institute, who used AlN buffer layers that were more than $5 \mathrm{~nm}$ in thickness [60]. These examples of polarity conversion depending on the thickness of the buffer layer are exactly similar to our case for MOCVD-GaN.

auto $\mathrm{V} / \mathrm{III}$ ratio

GaN buffer layers were deposited on nitrided sapphire under Ga-rich (lower V/III ratio: 2000) and optimized (V/III ratio: 20 000) conditions. Figure 16 shows AFM images for 20-min annealed buffer layers deposited under (a) optimum and (b) Ga-rich conditions before (on the left) and after (on the right) dipping them in $\mathrm{KOH}$ solution. The smooth surface of the optimum buffer layer turned into a rough surface, indicating $-\mathrm{c}$ polarity. In contrast, the surface for the Ga-rich buffer layer is resistant to the $\mathrm{KOH}$ solution, indicating $+\mathrm{c}$ polarity [32]. From these results, the III-rich condition might be considered to suppress the effect of $-\mathrm{c}$ polarity on nitrided sapphire substrates.

The FWHM of the Ga 3d spectrum detected by XPS for the former as-deposited sample was $2.2 \mathrm{eV}$ wider than that $(1.5-1.7 \mathrm{eV}$ by our analysis) for the latter layers [119], suggesting the existence of Ga metal or Ga that was weakly bonded with the N. Thus, the III-rich condition is suggested as being effective for obtaining a $+\mathrm{c}$ interface, as discussed in section 3.1.4 for MBE, as well as in MOCVD. Furthermore, the effect of the III-rich condition on the $+c$ polarity might be extended to the HVPE technique using the $\mathrm{GaCl}$ treatment mentioned in Sec. 3.3.

\section{auto Annealing conditions for the buffer layer}

The Ga-rich buffer layer is supposed to predominantly cohere and/or evaporate during the initial annealing. In fact, we confirmed that the buffer layer had completely evaporated within 7 min under an ambient of $\mathrm{NH}_{3}$ : $\mathrm{H} 2: \mathrm{N}_{2}=750: 750: 500 \mathrm{sccm}$. The sublimation could be suppressed by increasing in the amount of $\mathrm{N}_{2}$ (replacing the $\mathrm{H}_{2}$ ) in the gas ambient, and this annealed buffer then worked as a nucleation layer.

The annealing of the LT-buffer layer in MOCVD is a unique process. To add to the importance of the V/III ratio, the annealing conditions are also crucial to the polarity in terms of controlling the thickness of the buffer layer. $\mathrm{An}_{2}$ ambient should be used for thicker or III-poor buffer layers, while an $\mathrm{N}_{2}$ ambient is appropriate for a thin or III-rich layer in order to obtain a buffer layer of the optimum thickness. These correlations are very complex, depending on the individual growth apparatus. Our case is referred to in detail elsewhere [119].

Two recipes for obtaining $+\mathrm{c} \mathrm{GaN}$ on nitrided sapphire are; 1) the deposition of a thicker buffer layer under III-rich conditions, and 2) annealing of the layer for a short time under an $\mathrm{N}_{2}$ ambient. We suppose that Uchida et al. in Ref. 4, who deposited $+\mathrm{c}$ GaN on nitrided sapphire substrates, managed to use these correlations in their MOCVD apparatus.

\subsubsection{Recipe 2: Growth on H2 cleaned substrates}

$\mathrm{H}_{2}$ cleaning of sapphire substrates is indispensable for the growth of GaN with a smooth surface by two-step MOCVD. GaN films and GaN buffer layers on this type of substrate have $+c$ polarity. The basis of the recipe for preventing growth with $-\mathrm{c}$ polarity on $\mathrm{H}_{2}$ cleaned sapphire is in preventing the substrate from undergoing unintentional nitridation.

It was confirmed that nitridation using $\mathrm{NH}_{3}$ gas at temperatures higher than $700^{\circ} \mathrm{C}$ resulted in $-\mathrm{c}$ GaN films in our deposition system. In addition, the introduction of a flow of $\mathrm{NH}_{3}$ into the reactor, even for several seconds at $1080^{\circ} \mathrm{C}$, resulted in the growth of $-\mathrm{c} \mathrm{GaN}$ films. Therefore, unintentional nitridation probably takes place in the following circumstances; 1) when $\mathrm{NH}_{3}$ is introduced into the reactor during the decrease in substrate temperature for the deposition of the LT-buffer layer after $\mathrm{H}_{2}$ cleaning of the sapphire, and 2) when a longer time is used and annealing is carried out in an $\mathrm{H}_{2}$ ambient for a thin LT buffer layer (exposure of the sapphire surface). These factors indicate the importance of correct timing of the switching of the source gases when shifting to a subsequent part of the growth process.

Seelmann-Eggebert et al. have already pointed out that the occurrence of inversion domains in the films could mainly be attributed to poor process control during substrate cleaning and in the very initial stages of the nucleation process, preceding buffer growth [6]. It is 
supposed that the GaN with the hexagonal facets on a thin buffer layer that was reported in Ref. [3] might originate from the unintentional nitridation of the sapphire substrate.

\subsection{AIN buffer layer}

\subsubsection{Article 4: Comparison with LT-GaN buffer layers}

Figure 17 shows the dependence on annealing time of the XRD intensity of the (0002) peaks of $20 \mathrm{~nm}$ thick LT-GaN and AlN buffer layers deposited on $\mathrm{H}_{2}$ cleaned sapphire at $600^{\circ} \mathrm{C}$ under optimum conditions. Since the thermal annealing caused the crystallization of the buffer layer [124], the intensity of the $\mathrm{GaN}$ (0002) diffraction was enhanced when it was annealed for $10 \mathrm{~min}$. The extended annealing caused the layer to be thinner due to sublimation. It is worth noting here that it took double the time for the AlN to achieve maximum intensity in Figure 17, probably due to the lower mass-transportation and sublimation of the AlN buffer layer. This implies that the annealing conditions should be changed to suit the kind of buffer layer used [125] [126]. Indeed, the $\omega$ (0002) FWHM of GaN on an AlN buffer was improved from 400 (10 min annealing, which was the optimum time for the $\mathrm{GaN}$ buffer layer) to 240 arcsec, simply by annealing the AlN buffer for a longer time (20 min), as shown in Figure 17.

Figure 18 shows the relationship between the FWHM and the annealing time for $20 \mathrm{~nm}$ thick AlN and $\mathrm{GaN}$ buffer layers. The annealing time means the time interval from the end of the buffer layer deposition at $600^{\circ} \mathrm{C}$ till the start of the HT-GaN deposition at $1040^{\circ} \mathrm{C}$. After taking $7 \mathrm{~min}$ to reach $1040^{\circ} \mathrm{C}$, the annealing was maintained at $1040^{\circ} \mathrm{C}$ for the remainder of the time. All of the samples exhibited $+\mathrm{c}$ polarity. Although the best quality GaN was obtained on an AlN buffer layer, the values changed drastically in the narrow window of the annealing-time conditions. Figure 19 shows the FWHM and surface morphology (polarity) of HT-GaN films on nitrided sapphire substrates using AlN and GaN buffer layers of various thicknesses. The buffer layers were annealed for 10min. As discussed in Recipe 1, the material changed from $-\mathrm{c}$ to $+\mathrm{c}$ polarity (through a mixed polarity condition) for both types of buffer layer with increasing buffer layer thickness. However, the window for the AlN buffer layer is narrower, as in the case shown in Figure 18. Therefore, LT-GaN buffer layers may have an advantage for controlling the polarity of GaN films grown by MOCVD.

\subsubsection{Recipe 3: High-temperature AIN buffer layers}

HT-AlN buffer layers are useful in the growth of GaN films by MBE (Table (a) in Sec. 3.1). When an HT-AIN buffer layer was deposited at $1040^{\circ} \mathrm{C}$ in MOCVD, introducing $\mathrm{NH}_{3}$ at high temperature caused the uninten- tional nitridation of the sapphire (Recipe 2). Consequently, the GaN films had -c polarity with hexagonal facets. Two experiments have been undertaken to prevent this conversion to $-\mathrm{c}$ polarity when using an HTAlN buffer layer [127].

The TMA precursor was introduced into the reactor 10 seconds before the $\mathrm{NH}_{3}$ gas during the deposition of an HT-AIN buffer layer at $1040^{\circ} \mathrm{C}$. As expected, a $+\mathrm{c}$ $\mathrm{GaN}$ film was achieved. Judging from the deposition rate, the thickness of the Al metal layer was estimated to be $4 \AA$ during this 10 second period. In another experiment, a lower V/III ratio of less than 1800 was used for the AlN deposition at $1040^{\circ} \mathrm{C}$, which resulted in $+\mathrm{c} \mathrm{GaN}$ with a smooth surface, as shown in Figure 20. These two recipes, 1) the deposition of $\mathrm{Al}$ metal and 2) the use of a lower V/III ratio, seem to be consistent with the features seen in MBE.

\subsection{Polarity of the HT-GaN}

\subsubsection{Article 5: Correlation between the polarity and the growth process}

The polarity of HT-GaN was found to be attributable to that of the annealed buffer layer from the observations in the previous sections. During re-growth on a GaN template, the polarity could also attributed to that of the template, as recognized by Weyher et al. [128]. In our deposition system, the deposition rate of MOCVD-GaN films is limited by the arrival rate of the TMG source gas. Films are grown with changing deposition rates, ranging from 0.9 to $5.0 \mu \mathrm{m} / \mathrm{h}$. The polarities of these MOCVD-GaN films were identical with those of the annealed buffer layer on nitrided sapphire substrates [129]. This is inconsistent with MBE-GaN in terms of the kinetic effect highlighted in Sec. 3.1.3. Although the range of conditions used for the HT-GaN might be insufficient, we insist here that the polar structure at the interface of one of the underlying layers (the annealed LT-buffer layer or the template) would be the most crucial factor in determining the polarity of $\mathrm{GaN}$ films in MOCVD.

We have investigated the implications in the exact growth sequence and conditions in MOCVD. When summarizing them in Articles 1-5 and Recipes 1-3 with respect to the polarity, the relationship between the growth conditions and the polarity can be represented as a branching road map on a timing chart of the MOCVD process, as shown in Figure 21 [130]. The route is divided by the nitridation of the sapphire substrate. In order to achieve $+c$ GaN in MOCVD, the sapphire substrate must not be nitrided after the $\mathrm{H}_{2}$ cleaning. In the case where nitridation occurs, however, the polarity can still be controlled by modifying the preparation of the LT-buffer layer. 


\subsubsection{Recipe 4: Application of the road map}

The road map can be examined in several ways, not just for controlling the polarity, but also for depositing GaN films on various substrates. When GaN films are deposited on $\mathrm{Si}$-face $6 \mathrm{H}-\mathrm{SiC}$ substrates in MOCVD, it is well known that LT-AIN buffer layers should be used. When an LT-GaN buffer layer was used, part of the $\mathrm{SiC}$ surface was exposed during the time that the temperature was ramping because of the absence of a non-volatile intermediate layer (such as $\mathrm{AlGaN}$ ) at the interface of the sapphire substrates (Article 3). To overcome this unsuitable feature of using an LT-GaN buffer layer on a $\mathrm{SiC}$ substrate, it was annealed in an $\mathrm{N}_{2}$ ambient to suppress evaporation during the ramping of the temperature (Recipe 1 (3)). As expected, a GaN film with a smooth surface and of better quality was obtained on the $\mathrm{SiC}$ substrate using the LT-GaN buffer layer [131].

By modifying the timing of the introduction of the source gases according to Recipe 2, growth of GaN was achieved on a Si (111) substrate using only an AIN buffer layer. The key point of this was that the TMA and the $\mathrm{NH}_{3}$ gas should arrive simultaneously at the Si substrate in order to prevent the $\mathrm{Al}$ and $\mathrm{N}$ from alloying with the Si [132].

GaN films were deposited on $\left(\mathrm{La}_{0.29}, \mathrm{Sr}_{0.71}\right)\left(\mathrm{Al}_{0.65}\right.$, $\left.\mathrm{Ta}_{0.35}\right) \mathrm{O}_{3}$ (LSAT) (111) substrates, which have a lattice constant that corresponds to the $3 \times 3$ structure of $\mathrm{GaN}$ (0001) and a thermal expansion coefficient close to that of GaN. Since the LSAT substrate was deteriorated by $\mathrm{NH}_{3}$ and TMG gases at high temperature, an AlN layer was used as a blocking layer to protect the surface. The $\mathrm{GaN}$ film on the LSAT had $+\mathrm{c}$ polarity and its $\mathrm{GaN}$

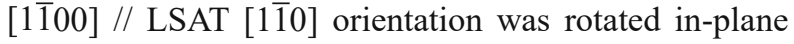
by $30^{\circ}$ against the expected orientation $(\mathrm{GaN}[2 \overline{1} \overline{1} 0] / /$ LSAT [110]) [133]. This was probably caused by the bond configuration of the surface of the LSAT substrate. In addition, $\mathrm{GaN}$ films on metal-face and O-face $\mathrm{LiGaO}_{2}(001)$ substrates had $+\mathrm{c}$ and $-\mathrm{c}$ polarity, respectively [134].

\section{Polarity dependence of properties and device performance}

The focus of our concern moves on to the polaritydependence of the properties of GaN films and device performance. Morkoc et al. [135] have already reviewed the band profile and the characteristics of electronic devices such as field effect transistors, considering the spontaneous and piezoelectric polarizations. The systematic variations of the 2DEG density and the band profile for an $\mathrm{AlGaN} / \mathrm{GaN} / \mathrm{AlGaN}$ hetero-structure were theoretically predicted by Ambacher et al., taking into account the thickness of the barrier layer, the com- position of the ternary alloy, the degree of strain, and the screening of the polarization field by free carriers [136].

In this section, the polarity-dependence of the optical properties of GaN films is discussed with respect to impurity-incorporation and defect formation. Furthermore, the structures of interfaces are summarized with respect to the contact formed between the metal and GaN polar surface, which are not fully discussed in these excellent reviews.

\subsection{Optical properties and defect formation}

Figure 22 shows depth profiles of $+\mathrm{c}$ and $-\mathrm{c} \mathrm{GaN}$ films. The yields of the matrix ions of $\mathrm{Ga}$ and $\mathrm{GaN}^{-}$are constant throughout the films. Comparing the results for both GaN films, C, O, and $\mathrm{Al}$ impurities are incorporated by one or two orders of magnitude more into $-\mathrm{c}$ $\mathrm{GaN}$, while Si impurities have an incorporation rate that is several times higher into $+\mathrm{c} \mathrm{GaN}$ [137]. Consistent with the higher level of impurities, the carrier concentration for $-\mathrm{c} \mathrm{GaN}$ was much higher than that for $+\mathrm{c} \mathrm{GaN}$, in spite of the growth conditions (the V/III ratio) and the growth rate. The dependence of the impurity incorporation can be explained either by the difference in the adsorption energy between the matrix elements and the impurities on the polar surface [138] or by differences in the mode of the growth.

$\mathrm{Li}$ et al. found that the doping behavior of $\mathrm{Mg}$ and the resulting conductivity of the doped layers in MBEGaN strongly depends on the polarity of the GaN [139]. In fact, $\mathrm{Mg}$ was incorporated by up to a factor of 30 times more into $+\mathrm{c} \mathrm{GaN} \mathrm{[140].} \mathrm{Activation} \mathrm{of} \mathrm{the} \mathrm{p-type}$ dopants was achieved for $+\mathrm{c} \mathrm{GaN}$. One of the reasons why this was possible is thought to be that $\mathrm{C}$ and $\mathrm{O}$ impurities are incorporated more into -c GaN [141]. GaN films on bulk GaN single crystals with -c polarity grown by MOCVD [142] and films on $\mathrm{ZnO}$ with O-face polarity grown by MBE [143] were also found to contain more oxygen impurities in the $-\mathrm{c} G a N$, respectively, which was confirmed by IR and SIMS. This impuritydependence on the polarity is consistent with our experiments with MOCVD-GaN, except for the case of $\mathrm{Si}$ [137]. Comparable Si incorporation into both types of $\mathrm{GaN}$ films has been suggested by both $\mathrm{Ng}$ et al. and ourselves, while Li et al. reported higher incorporation of $\mathrm{Si}$ in $-\mathrm{c}$ GaN. The issue of Si impurity incorporation is still therefore controversial.

The dependence of impurity incorporation on the polarity resulted in differences in the IR [142] and Raman spectra [41] as in Sec. 2.1. The dependence of the optical properties and of defect formation on the polarity was investigated on our $+\mathrm{c}$ and $-\mathrm{c} \mathrm{GaN}$ films. The PL spectrum of $+c \mathrm{GaN}$ at $8 \mathrm{~K}$ [144] exhibits free A and $\mathrm{B}$ exciton emission $[\mathrm{FE}(\mathrm{A})$ and $\mathrm{FE}(\mathrm{B})]$ at 3.492 and $3.499 \mathrm{eV}$, respectively, as shown in Figure 23 (a). The 
recombination of the first excited states of the $\mathrm{A}$ exciton $\left[\mathrm{FE}\left(\mathrm{A}_{\mathrm{n}=2}\right)\right]$ is also found at $3.510 \mathrm{eV}$. These assignments are based on the position of the energies of the respective exciton absorption peaks. The sample also exhibits exciton recombination at 3.486 and $3.464 \mathrm{eV}$, which are due to the bound-to-neutral donor $\left(D^{0}, X\right)$ and neutral deep acceptor $\left(A^{0}{ }_{d}, X\right)$ transitions, respectively. The PL peak at $300 \mathrm{~K}$ is assigned to the free exciton emission, as revealed from Figure 23 (c). Conversely, -c GaN exhibits a rather broader PL band and an absorption tail, as in Figure 23 (b) and (d). The spectrum at $8 \mathrm{~K}$ exhibits a peak at $3.475 \mathrm{eV}$ and a shoulder around $3.45 \mathrm{eV}$. Since the residual electron density of the $-\mathrm{c} \mathrm{GaN}$ is as high as $3.5 \times 10^{18} \mathrm{~cm}^{-3}$, the disappearance of excitonic absorption due to Coulomb screening by the increase in temperature above $75 \mathrm{~K}$ is reasonable. However, -c GaN exhibits a Stokes shift of nearly $20 \mathrm{meV}$ at $300 \mathrm{~K}$, although high quality Si-doped $+c \mathrm{GaN}$ (with nearly the same electron density of $2.2 \times 10^{18} \mathrm{~cm}^{-3}$ ) did not show any Stokes shift at $300 \mathrm{~K}$. Therefore, the formation of an impurityinduced band tail is probable in $-\mathrm{c} \mathrm{GaN}$, which subsequently causes band gap narrowing due to potential fluctuations and inhomogeneous distribution of the fixed charges. The donor impurity is considered to be $\mathrm{O}$, which is more readily incorporated into $-\mathrm{c} \mathrm{GaN}$, as revealed by SIMS in Figure 22. To determine the possibility for the incorporation of acceptor-type defects such as Ga vacancies [145], mono-energetic slow positron annihilation measurements were carried out. Indeed, the $\mathrm{S}$ parameter of $-\mathrm{c} \mathrm{GaN} \mathrm{[146]} \mathrm{is} \mathrm{greater} \mathrm{than} \mathrm{that} \mathrm{of}+\mathrm{c}$ $\mathrm{GaN}$, as shown in Figure 24. The fitting results of the relationship between $\mathrm{E}$ and $\mathrm{S}$ are also shown by the solid lines, and the diffusion lengths of positrons are derived to be $23 \mathrm{~nm}$ for $+\mathrm{c} \mathrm{GaN}$ and $4.8 \mathrm{~nm}$ for $-\mathrm{c} \mathrm{GaN}$. These results imply that $-\mathrm{c} \mathrm{GaN}$ contains a higher density of vacancy-type defects or defect-complexes than $+\mathrm{c} \mathrm{GaN}$. Therefore, the formation of extended band-tail states in $-\mathrm{c} \mathrm{GaN}$ is considered to be due to the simultaneous distribution of donors and acceptor-type vacancy defects, which occurred during the growth of the $-\mathrm{c}$ polarity GaN material.

\subsection{Schottky barrier}

Karrer et al. characterized the influence of the polarity on the electrical properties (I-V and C-V measurements) of Pt Schottky diodes on Si-doped epitaxial GaN layers with $+c$ and $-c$ polarity [8]. An effective Schottky barrier height $(\mathrm{SBH})$ was measured between $\mathrm{Pt} / \mathrm{GaN}$ by using the I-V characteristics as a function of the ideality factor. The value of the SBH was determined to be 1.1 and $0.9 \mathrm{eV}$ for devices on $+\mathrm{c}$ and $-\mathrm{c} \mathrm{GaN}$ with the same carrier density $\left(\mathrm{n}_{\mathrm{e}}=6-10 \times 10^{17} \mathrm{~cm}^{-3}\right)$ respectively. Jang et al. also reported that the SBH determined by I-V charac- teristics on $+\mathrm{c} \mathrm{GaN}\left(\mathrm{n}_{\mathrm{e}}=3 \times 10^{16} \mathrm{~cm}^{-3}\right)$ was higher by 0.31 $\mathrm{eV}$ than that on $-\mathrm{c}$ GaN $\left(\mathrm{n}_{\mathrm{e}}=1 \times 10^{17} \mathrm{~cm}^{-3}\right)$ [44], which was consistent with Karrer's report in terms of the difference in the SBH. However, the SBH values measured by $\mathrm{C}-\mathrm{V}$ were $1.75 \mathrm{eV}$ for the $+\mathrm{c} \mathrm{GaN}$ and $0.85 \mathrm{eV}$ for $-\mathrm{c}$ GaN (Karrer et al). Furthermore, the energy of the valence-band edge for the $+\mathrm{c} \mathrm{GaN}$ surface was higher by $1.4 \mathrm{eV}$ than that for -c GaN measured by high resolution photoemission spectroscopy (HRPES). There are large differences in the SBH of GaN diodes obtained from C$\mathrm{V}$ and $\mathrm{I}-\mathrm{V}$ measurements. Since these $\mathrm{Pt} / \mathrm{GaN}$ samples were prepared on GaN deposited by the MBE method, inversion domains (IDs) containing - c polarity should exist in the $+c$ GaN. A small fraction of $-c$ IDs with lower barrier height may be regarded as a reason for large difference in the results between the I-V and the C$\mathrm{V}$ measurements. Since a larger diode current may be selectively injected into -c IDs, the SBH can be underestimated from the measured I-V characteristics. On the other hand, since the ratio of the areas of the two domains contributes to the SBH determined by the $\mathrm{C}-\mathrm{V}$ measurement, a small quantity of -c IDs would hardly have any influence on the result.

Rickert et al. studied the SBH for thin metal overlayers of $\mathrm{Au}, \mathrm{Al}, \mathrm{Ni}, \mathrm{Ti}, \mathrm{Pt}$ and $\mathrm{Pd}$ on n- and p-type $+\mathrm{c}$ GaN samples using synchrotron radiation-based x-ray photoemission spectroscopy [147]. Figure 25 shows the values of the SBH of the six kinds of metals as a function of the work function of the metals. The relationship between the SBH and the work function did not obey the perfect Schottky barrier model. The change in the barrier height was smaller than the value expected from the change in the metal work function. These results indicate the importance of the effect of the surface state and the interface state (refer to Sec. 5.4). To explain this appropriately, a model that takes into account the pinning of the Fermi level at the surface would be required. The position of the Fermi level on the surface of the GaN can be changed by the kind of metal, the conduction type of the $\mathrm{GaN}$, or the chemical treatment of the surface. In addition, the $\mathrm{SBH}$ for a $\mathrm{Pt} / \mathrm{n}-\mathrm{GaN}$ structure was reported to be about $1.6 \mathrm{eV}$, which is comparable to that obtained by $\mathrm{C}-\mathrm{V}$ measurement and HRPES.

\subsection{Ohmic contact}

The formation of ohmic contacts has been achieved on many semiconductors by either high impurity doping in the contact region or by decreasing the tunneling barrier thickness at the metal / semiconductor interface. In the case of nitride semiconductors, the formation of an ohmic contact can be expected owing to the polarization effect.

Jang et al. compared the characteristics of an ohmic contact using $\mathrm{Ti} / \mathrm{Al} / \mathrm{Ni} / \mathrm{Au}$ metal on $+\mathrm{c} \mathrm{GaN}$ with that on 
a -c GaN sample [44]. The contact resistivities, as determined by the transfer length method (TLM), were $8.3 \times 10^{-4} \Omega \mathrm{cm}^{2}$ for the $+\mathrm{c}$ sample and $7.0 \times 10^{-2} \Omega \mathrm{cm}^{2}$ for the $-\mathrm{c}$ sample. These samples were annealed at $700^{\circ} \mathrm{C}$ for $1 \mathrm{~min}$. Although the net carrier concentration of the c sample was higher than that of $+c$ sample, the contact resistivity on the $+\mathrm{c}$ GaN was lower by two orders of magnitude than that on the $-\mathrm{c}$ GaN.

It is well known that a thin AlN layer can be formed at the interface between the metal and the GaN after annealing a $\mathrm{Ti} / \mathrm{Al}$ contact at a temperature higher than $400^{\circ} \mathrm{C}$. Luther et al. explained the lower contact resistivity for a $+\mathrm{c}$ sample as being due to polarization, that is, a 2DEG could be induced by polarization at the $+\mathrm{c}$ AlN/ $\mathrm{GaN}$ interface, but not at the $-\mathrm{c}$ interface [148]. Therefore, the effective $\mathrm{SBH}$ for the tunneling probability of an electron through the AIN epilayer in a $+c$ sample is considered to be much higher than that for a $-\mathrm{c}$ sample. Kwak et al. investigated the effects of polarity on the electrical properties of Ti/Al contacts for n-type GaN [149]. They reported that $\mathrm{Ti} / \mathrm{Al}$ contacts on n-type $+\mathrm{c}$ $\mathrm{GaN}$ become ohmic with a contact resistivity of $5 \times 10^{-}$ ${ }^{5} \Omega \mathrm{cm}^{2}$, while a Schottky contact with a barrier height of over $1 \mathrm{eV}$ was formed for contacts on n-type-c GaN.

The effects of polarity on ohmic contacts to p-type $\mathrm{GaN}$ were also investigated. Band bending, which is caused by the polarization charge of a thin InGaN capping layer on a $\mathrm{p}-\mathrm{GaN}$ layer, is utilized to realize the ohmic contact. Gessmann et al. discussed the effect of thin strained cap layers on the contact resistance of $p$ type $+c \mathrm{GaN}$ [150] [151]. Two cases were investigated; a GaN cap/AlGaN structure and an InGaN cap/GaN structure. The electric field in the strained cap layers can reduce the thickness of the tunneling barrier at the metal/semiconductor interface. Since band bending due to the capping layer can be induced by an internal electric field, the thickness of the capping layer must be optimized so that two conditions, the formation of the 2DEG and sufficient tunneling probability for holes, could be satisfied simultaneously. The specific contact resistances were obtained experimentally using the TLM-method. These were $6 \times 10^{-3} \Omega \mathrm{cm}^{2}$ for $\mathrm{InGaN}$ $(2 \mathrm{~nm}) / \mathrm{p}-\mathrm{GaN}\left(\mathrm{Ni} / \mathrm{Au}\right.$ contact: annealing at $\left.500^{\circ} \mathrm{C}\right)$ and $7 \times 10^{-4} \Omega \mathrm{cm}^{2}$ for $\mathrm{GaN}(10 \mathrm{~nm}) / \mathrm{AlGaN}(\mathrm{Pd} / \mathrm{Au}$ contact: annealing at $500^{\circ} \mathrm{C}$ ). These results indicated the advantageous effect of polarization fields in the cap layer on the reduction of ohmic contact resistance.

\subsection{Surface state}

Surface or interface states are probably not taken into account in the analysis of the experimental data mentioned in Sec. 5.3 and 5.4. In addition, the surface state density has seldom been taken into consideration in the- oretical calculations of the band structure. However, Ridley estimated the electron populations induced by spontaneous and piezoelectric polarization in n-type $+c$ AlGaN/GaN hetero-structures by using elementary electrostatic theory [152]. He considered several points, such as the existence of the donor density in the barrier layer, the surface charge (adsorbed ion and surface state population change) of the $\mathrm{GaN}$ buffer layer and/or the AlGaN barrier layer. It is suggested that the thickness of the surface barrier layer should be optimized according to the pinning position of the Fermi level by the surface states, though the 2DEG density induced at the heterointerface must become larger with increasing thickness of the barrier layer.

Several methods of reducing the surface states have been proposed. The treatment with $\left(\mathrm{NH}_{4}\right)_{2} \mathrm{~S}_{\mathrm{x}}$ carried out by Lin et al. [153] caused the band bending of a p-type $+\mathrm{c}$ GaN surface to release by $0.25 \mathrm{eV}$. The interface states of an n-type $+\mathrm{c}$ GaN surface were decreased to $1 \times 10^{12} \mathrm{~cm}^{-2} \mathrm{eV}^{-1}$ by treatment with an $\mathrm{N}_{2}$ plasma, which was about $1 / 5$ of the level for a non-treated surface (experiment carried out by Hashizume et al. [154]). Furthermore, a decrease in the electron affinity of Csadsorbed AlN [155] and GaN [156] surfaces was observed due to the effect of the Cs-surface dipole, which was formed by an initial interaction between the Cs and the empty surface states. Unfortunately, these experimental data were not discussed in connection with spontaneous polarization, which induced sheet charges. Although a method of controlling the surface states has not yet been established, the control of charges caused by surface states and spontaneous polarization is considered to be one of the new topics that could realize new functionality from nitride semiconductors.

\section{Summary and Remarks}

The evaluation and control of crystalline polarity are important because the spontaneous and piezoelectric polarizations are large enough to influence the band-profile of hetero-structures in the III-nitride system (Sec. 2). These polarizations can be used not only for controlling the SBH and achieving ohmic contacts (Sec. 5.2 to 5.4), but also for exploring new functionalities in III-nitrides (Sec. 5.5). Taking it into account that impurities $(\mathrm{O}, \mathrm{C}$, and $\mathrm{Al})$ and vacancy-type defects $\left(\mathrm{V}_{\mathrm{Ga}}\right)$ are more readily incorporated into -c GaN films (Sec. 5.1), it is necessary to grow $+\mathrm{c}$ GaN films with smooth surfaces.

GaN films grown by MBE, PLD, HVPE and MOCVD have been reviewed, mainly with respect to the control of polarity. The first three are based on the published literature, while the last is based on our studies. Focusing on the growth conditions in the substrate treatment and/or the preparation of LT-buffer layers, a 
set of conditions for obtaining $+\mathrm{c}$ GaN films is provided for each growth method, as follows;

(1) MBE and PLD (Sec. 3.1 and 3.2)

a) Use an AIN buffer layer deposited on a sapphire substrate at higher temperature under a higher growth rate (III-rich condition)

b) Insertion of $\mathrm{Mg}, \mathrm{Al}$ and $\mathrm{Ga}$ metal layers at the interface

c) Use of a thicker GaN buffer layer.

(2) HVPE (Sec. 3.3)

a) $\mathrm{GaCl}$ treatment of the sapphire substrate

b) Deposition of $\mathrm{ZnO}$ and $\mathrm{AlN}$ layers in an isolated system

c) Use of a thicker LT-GaN buffer layer.

(3) MOCVD (Sec. 4)

a) Prevent $\mathrm{H}_{2}$ cleaned sapphire substrates from undergoing unintentional nitridation.

b) Use thicker LT-GaN buffer layers deposited under a lower V/III ratio on nitrided sapphire substrates.

c) Much lower V/ III ratio for HT-AIN buffer layers on sapphire substrates.

A III-rich condition at the interface of the sapphire substrate is mostly decisive in the disparate growth techniques. Indeed, the III-rich condition (lower V/III ratio) has been used during the deposition of LT-buffer layers on $\mathrm{H}_{2}$-cleaned sapphire substrates in our MOCVD. The initial growth at the interface of the sapphire under the III-rich condition should occur in an equilibrium state leading to $+\mathrm{c}$ polarity, though the kinetic effect is still unclear.

CAICISS can be used to evaluate the polarity of thin films such as buffer layers (Sec. 2.4). The polarity of an LT-buffer layer was detected for the first time by using CAICISS (Sec. 4.3). We have studied the role of the LTbuffer layer and its implications in each process for GaN film growth by two-step MOCVD, not only in terms of controlling the polarity but also for improving material quality. A road map representing the correlation between the polarity and the growth conditions in MOCVD has been made, as shown in Figure 21. Indeed, the polarity can be managed from $+\mathrm{c}$ to $-\mathrm{c}$ though mixed polarity by systematically varying the conditions used in MOCVD-GaN. Although the initial growth on sapphire would determine the polarity of the epitaxial materials, the polarity can be controlled by understanding the structure of the LT-buffer layer and its implications for the MOCVD process. It can be concluded through these studies that the polar structure at the interface of an annealed LT-buffer layer is the most crucial factor in determining the polarity of a GaN film.
Recently, the importance of polarity was highlighted in the state-of-the-art growth of InN films [157] [158], and-c GaN with a smooth surface has apparently been obtained by MOCVD [159]. Moreover, we have discovered that an $\mathrm{HNO}_{3}$ treatment of $\mathrm{H}_{2}$-cleaned sapphire substrates resulted in $-\mathrm{c}$ GaN film growth in MOCVD [160]. Thus, even more interesting results relating to film polarity have been reported. We intend to further promote studies of the polarity of III-nitrides for applications that utilize the effects of polarity.

\section{ACKNOWLEDGMENTS}

The authors would like to thank the students who have been working in our laboratory for conducting their experiments. We would like to express special thanks to Dr. Ohnishi (Univ. of Tokyo) for his intense collaborations in CAICISS analysis, and for his valuable discussions. We gratefully acknowledge collaborations from Mr. Mizuno and Mr. Furusawa for CAICISS analysis of InGaN SQWs, for Dr. Chichibu for his optical measurements, for Dr. Uedono for his positron annihilation measurements and for Dr. Romano for her X-TEM observations. We are grateful to many collaborators who have supported and encouraged our research. This work was supported by a Grant-in-Aid for Developmental Scientific Research (No. 14703024) and by the Asahi Glass Research Foundation.

\section{REFERENCES}

[1] H. Amano, N. Sawaki, I. Akasaki, Y. Toyoda , Appl. Phys. Lett. 48, 353-355 (1986).

[2] E. S. Hellman, MRS Internet J. Nitride Semicond. Res. 3, 11 (1998).

[3] S. Nakamura, Jpn. J. Appl. Phys. 30, L1705-L1707 (1991).

[4] K. Uchida, A. Watanabe, F. Yano, M. Kouguchi, T. Tanaka, S. Minagawa, J. Appl. Phys. 79, 3487-3491 (1996).

[5] M. Katayama, E. Nomura, N. Kanekawa, H. Soejima, M. Aono, Nucl. Instrum. Methods B 33, 857 (1988).

[6] M. Seelmann-Eggebert, J. L. Weyher, H. Obloh, H. Zimmermann, A. Rar, S. Porowski, Appl. Phys. Lett. 71, 2635-2637 (1997).

[7] F. Bernardini, V. Fiorentini, D. Vanderbilt, Phys. Rev. B 56, R10024 (1997).

[8] U. Karrer, O. Ambacher, M. Stutzmann, Appl. Phys. Lett. 77, 2012 (2000).

[9] S. F. Chichibu, A. C. Abare, M. S. Minsky, S. Keller, S. B. Fleischer, J. E. Bowers, E. Hu, U. K. Mishra, L. A. Coldren, S. P. DenBaars, T. Sota, Appl. Phys. Lett. 73, 2006 (1998).

[10] F. Bernardini, and V. Fiorentini, http://xxx.lanl.gov/abs/ condmat/9808098

[11] N. Maeda, T. Nishida, N. Kobayashi, M. Tomizawa, Appl. Phys. Lett, 73 (1998). 
[12] T. Sasaki, T. Matsuoka , J. Appl. Phys. 64, 4531-4535 (1988).

[13] SY Ren, JD Dow, Appl. Phys. Lett. 69, 251-253 (1996).

[14] SY Ren, JD Dow, J. Electron. Mater. 26, 341-346 (1997).

[15] C. J. Sun, P. Kung, A. Saxler, H. Ohsato, E. Bigan, M. Razeghi, D. K. Gaskill, J. Appl. Phys. 76, 236-241 (1994).

[16] S. Fuke, H. Teshigawara, K. Kuwahara, Y. Takano, T. Ito, M. Yanagihara, K. Ohtsuka, J. Appl. Phys. 83, 764 (1998).

[17] A. Koukitu, M. Mayumi, Y. Kumagai, J. Cryst. Growth 246, 230 (2002).

[18] F.A. Ponce, D.P. Bour, W.T. Young, M. Saunders, J.W. Steeds, Appl. Phys. Lett. 69, 337-339 (1996).

[19] Z. Liliental-Weber, C. Kisielowski, S. Ruvimov, Y. Chen, J. Washburn, I. Grzegory, M. Bockowski, J. Jun, S. Porowski, J. Electron. Mater. 25, 1545 (1996).

[20] LT Romano, JE Northrup, MA O'Keefe, Appl. Phys. Lett. 69, 2394-2396 (1996).

[21] J. L. Rouviere, M. Arlery, R. Niebuhr, K. H. Bachem, Olivier Briot, MRS Internet J. Nitride Semicond. Res. 1, 33 (1996).

[22] S. Keller, B. P. Keller, Y.-F. Wu, B. Heying, D. Kapolnek, J. S. Speck, U. K. Mishra, S. P.DenBaars, Appl. Phys. Lett. 68, 1525-1527 (1996).

[23] F. A. Ponce, D. P. Bour, W. Gotz, P. J. Wright, Appl. Phys. Lett. 68, 57-59 (1996).

[24] J. N. Stirman, F. A. Ponce, A. Pavloska, I. S. T. Tsong, D. J. Smith, Appl. Phys. Lett. 76, 822 (2000).

[25] N. Jiang, T. J. Eustis, J. Cai, F. A. Ponce, J. C. H. Spence, J. Silox, Appl. Phys. Lett. 80, 389 (2002).

[26] X. Kong, G. Q. Hu, X. F. Duan, Y. Lu, X. Liu, Appl. Phys. Lett. 81, 1990 (2002).

[27] H. W. Zandbergen, J. Janzen, A. R. A. Zauner, J. L. Weyher, J. Cryst. Growth 210, 167 (2000).

[28] A. R. Smith, R. M. Feenstra, D. W. Greve, J. Neugebauer, J. E. Northrup, Phys. Rev. Lett. 79, 3934 (1997).

[29] R. Held, G. Nowak, B.E. Ishaug, S.M. Seutter, A. Parkhomovsky, A.M. Dabiran, P.I. Cohen, I. Grzegory, S. Porowski, J. Appl. Phys. 85, 7697-7704 (1999).

[30] AR Smith, RM Feenstra, DW Greve, M-S Shin, M Skowronski, J Neugebauer, J Northrup, J. Vac. Sci. Technol. B 16, 2242-2249 (1998).

[31] R. M. Feenstra, J. E. Northrup, Jörg Neugebauer, $M R S$ Internet J. Nitride Semicond. Res. 7, 3 (2002).

[32] J. L. Weyher, S. Müller, I. Grzegory, S. Porowski, J. Cryst. Growth 182, 17-22 (1997).

[33] D. Li, M. Sumiya, S. Fuke, D. Yang, D. Que, Y. Suzuki, Y. Fukuda, J. Appl. Phys. 90, 4219 (2001).

[34] M. Losurdo, M. Giangregorio, P. Capezzuto, G. Bruno, G. Namkoong, W. A. Doolittle, A. S. Brown, Mater. Res. Soc. Symp. Proc. 722, K3.4.1 (2002).

[35] "CAICISS analysis of GaN gilms grown on sapphire substrate by MOCVD method", M. Sumiya, T. Ohnishi, H. Teshigawara, M. Tanaka, I. Ohkubo, M. Kawasaki, M. Yoshimoto, K. Ohtsuka, H. Koinuma, and S. Fuke, Proc. of the $2^{\text {nd }}$ Intern. Symp. On Blue Laser and Light Emitting Diodes, Chiba, Japan, 339 (1998)
[36] M. Sumiya, M. Tanaka, K. Ohtsuka, S. Fuke, T. Ohnishi, I. Ohkubo, M. Yoshimoto, H. Koinuma, M. Kawasaki, Appl. Phys. Lett. 75, 674 (1999).

[37] S. Shimizu, Y. Suzuki, T. Nishihara, S. Hayashi, M. Shinohara, Jpn. J. Appl. Phys. 37, L703 (1998).

[38] A. Kazimirov, N. Faleev, H. Temkin, M. J. Bedzyk, V. Dmitriev, Yu. Melnik, J. Appl. Phys. 89, 6092 (2001).

[39] M. Tabuchi, N. Matsumoto, Y. Takeda, T. Takeuchi, H. Amano, I. Akasaki, J. Cryst. Growth 189/190, 291 (1998).

[40] R. Dimitrov, V. Tilak, M. Murphy, W. J. Schaff, L. F. Eastman, A. P. Lima, C. Miskys, O. Ambacher, M. Stutzmann, Mater. Res. Soc. Symp. Proc. 622, T4.6.1 (2000).

[41] "Raman characterizatiion of an intentionally created Inversion domain boudary in GaN", A. Cros, N. V. Joshi, T. Smith, A. Cantarero, G. Martines-Criado, O. Ambacher and M. Stutzmann, the $5^{\text {th }}$ international Conference on Nitrides semiconductors, Nara, Japan. Technical Digest Mo-P1.109 (2003)

[42] K. M. Jones, P. Visconti, F. Yun, A. A. Baski, H. Morkoc, Appl. Phys. Lett. 78, 2497 (2001).

[43] B. J. Rodriguesz, A. Gruverman, A. I. Kingon, R. J. Nemanich, O. Ambacher, Appl. Phys. Lett. 80, 4166 (2002).

[44] H. W. Jang, J. H. Lee, J. L. Lee, Appl. Phys. Lett. 80, 3955 (2002).

[45] B Daudin, JL Rouviere, M Arlery, Appl. Phys. Lett. 69, 2480-2482 (1996).

[46] M. M. Sung, J. Ahn, V. Bykov, J. W. Rabalais, D. D. Koleske, A. E. Wickenden, Phys. Rev. B 54, 14652-14663 (1996).

[47] M. Katayama, R. S. Williams, M. Kato, E. Nomura, M. Aono, Phys. Rev. Lett. 66, 2762 (1991).

[48] Papers related to CAICISS analysis are listed at http:// cobalt.ele.eng.osaka-u.ac.jp/ katayama/caiciss.html

[49] T. Ohnishi Doctoral thesis entitled by 'Atomic scale analysis and engineering of oxide thin films', Tokyo Inst. of Tech. 1999

[50] S. Sonoda, S. Shimizu, Y. Suzuki, K. Balakrishnan, J. Shirakashi, H. Okumura, T. Nishihara, M. Shonohara, Jpn. J. Appl. Phys. 38, L1219 (1999).

[51] T. Ohnishi, A. Ohtomo, M. Kawasaki, K. Takahashi, M. Yoshimoto, H. Koinuma, Appl. Phys. Lett. 72, 824 (1998).

[52] M. Sumiya, S. Nakamura, S. F. Chichibu, K. Mizuno, M. Furusawa, M. Yoshimoto, Appl. Phys. Lett. 77, 2512 (2000).

[53] C. Heinlein, J. Grepstad, T. Berge, H. Riechert, Appl. Phys. Lett. 71, 341 (1997).

[54] S. Mikroulis, A. Georgakilas, A. Kostopoulos, V. Cimalla, E. Dimakis, Ph. Komniou, Appl. Phys. Lett. 80, 2886 (2002).

[55] G. Namkoong, W. A. Doolittle, A. S. Brown, M. Losurdo, P. Capezzuto, G. Bruno, J. Appl. Phys. 91, 2499 (2001), J. Vac. Sci. Technol. B 20, 1221 (2002).

[56] S. Sonoda, S. Shimizu, X. Q. Shen, S. Hara, H. Okumura, Jpn. J. Appl. Phys. 39, L202 (2000).

[57] N Grandjean, J Massies, M Leroux, Appl. Phys. Lett. 69, 2071-2073 (1996).

[58] R. Di Felice, J. E. Northrup, Appl. Phys. Lett. 73, 936 (1998). 
[59] S. Sonoda, S. Shimizu, Y. Suzuki, K. Balakrishnan, J. Sirakashi, H. Okumura, Jpn. J. Appl. Phys. 39, L73 (2000). [60] R. Dimitrov, M. Murphy, J. Smart, W. Schaff, J. S. Shealy, L. F. Eastman, O. Ambacher, M. Stutzmann, J. Appl. Phys. 87, 3375 (2000).

[61] C. Piquette, P. M. Bridger, R. A. Beach, T. C. McGill, Mater. Res. Soc. Symp. Proc. 537, G3.77 (1999).

[62] Gon Namkoong, W. Alan Doolittle, April S. Brown, Maria Losurdo, Maria M. Giangregorio, Giovanni Bruno, J. Cryst. Growth 252, 159 (2003).

[63] F. Hasegawa, O. Takahashi, T. Nakayama, R. Souda, Phys. Stat. Sol. B 228, 549 (2001).

[64] O. H. Hughes, T. S. Cheng, S. V. Novikov, C. T. Foxon, D. Korakakis, N. J. Jeffs, J. Cryst. Growth 201/201, 388 (1999).

[65] D. Huang, P. Visconti, K. M. Jones, M. A. Reshchikov, F. Yun, A. A. Baski, T. King, H. Morkoc, Appl. Phys. Lett. 78, 4145 (2001).

[66] K. Xu, N. Yano, A. W. Jia, A. Yoshikawa, K. Takahashi, Phys. Stat. Sol. B 228, 523 (2001).

[67] D. H. Lim, K. Xu, Y. Taniyasu, K. Suzuki, S. Arima, B. Liu, K. Takahashi, A. Yoshikawa, Proc. Int. Workshop on Nitride Semicond, 1, 150 (2000).

[68] Y. S. Park, H. S. Lee, J. H. Ha, H. J. Kim, Sang Man Si, Hwa-Mok Kim, T. W. Kang, Jae Eung Oh, Appl. Phys. Lett. 94, 800 (2003).

[69] A. Kikuchi, T. Yamada, K. Kusakabe, D. Sugihara, S. Nakamura, K. Kishino, 1, 154 (2000).

[70] S. Yoshida, J. Appl. Phys. 87, 1673 (1997).

[71] S. Yoshida, Oyo Buturi 68, 787 (1999)

[72] A. Ishida, E. Yamamoto, K. Ishino, K. Ito, H. Fujiyasu , Y. Nakanishi, Appl. Phys. Lett. 67, 665-666 (1995).

[73] K. Okuno, M. Sumiya, S. Fuke, 11a-N-3, Extended Abstract (The 62nd Fall Meeting 2001) The Japan Society of Applied Physics and Related Societies

[74] V. Ramachandran, R. M. Feenstra, W. L. Sarney, L. Salamanca-Riba, J. E. Northrup, L. T. Romano, D. W. Greve, Appl. Phys. Lett. 75, 808 (1999).

[75] L. T. Romano, J. E. Northrup, A. J. Ptak, T. H. Myers, Appl. Phys. Lett. 77, 2479 (2000).

[76] N. Grandjean, A. Dussaigne, S. Pezzagna, P. Vennegues, J. Cryst. Growth 251, 460 (2003).

[77] J. E. Northrup, Appl. Phys. Lett. 82, 2278 (2003).

[78] EJ Tarsa, B Heying, XH Wu, P Fini, SP DenBaars, JS Speck, J. Appl. Phys. 82, 5472-5479 (1997).

[79] R. Held, D. E. Crawford, A. M. Johnston, A. M. Dabiran, P. I. Cohen, Surf. Rev. Lett. 5, 913-934 (1998).

[80] T. H. Myers, L. S. Hirsch, L. T. Romano, M. R. Richards-Babb, J. Vac. Sci. Technol. B 16, 2261 (1998).

[81] I. Ohkubo, A. Ohtomo, T. Ohnishi, Y. Matsumoto, H. Koinuma, M. Kawasaki, Surf. Sci. Lett 443, L1043 (1999).

[82] O. Takahashi, T. Nakayama, R. Souda, F. Hasegawa, Phys. Stat. Sol. B 228, 529 (2001).

[83] J.H. Edgar, S.Strite, I.Akasaki, H.Amano, C.Wetzel, Properties, processing and applications of GaN and related semiconductors, (INSPEC, Institution of Electrical Engineers, London, UK, 1999), .

[84] J. E. Northrup, R. Di Felice, J. Neugebauer, Phys. Rev. B 55, 13878 (1997).
[85] R. D. Dispute, H. Wu, K. Jagannadham, J. Narayan, Mater. Res. Soc. Symp. Proc. 395, 325 (1995).

[86] J. Ohta, H. Fujioka, M. Ohsima, Appl. Phys. Lett. 83, 3060 (2003).

[87] J. Ohta, H. Fujioka, M. Furusawa, A. Sasaki, M. Yoshimoto, H. Koinuma, M. Sumiya, M. Ohsima, J. Cryst. Growth 237-239, 1153 (2002).

[88] H. Zhou, T. Rupp, F. Phillipp, G. Henn, M. Gross, A. Ruhm, H. Schroder, J. Appl. Phys. 93, 1933 (2003).

[89] J. Ohta, H. Fujioka, M. Oshima, K. Fujiwara, A. Ishii, Appl. Phys. Lett. 83, 3075 (2003).

[90] S. Oktybrsky, K. Dovidenko, A. K. Sharma, V. Joshkin, J. Narayan, Mater. Res. Soc. Symp. Proc. 537, G6.43 (1999).

[91] A Usui, H Sunakawa, A Sakai, AA Yamaguchi, Jpn. J. Appl. Phys. 36, L899 (1997).

[92] Y. Kawaguchi, S. Nambu, H. Sone, M. Yamaguchi, H. Miyake, K. Hiramatsu, N. Sawaki, Y. Iyechika, T. Maeda, Mater. Res. Soc. Symp. Proc. 537, G4.1 (1999).

[93] H. P. Maruska, J. J. Tietjen, Appl. Phys. Lett. 15, 327 (1969).

[94] B. Monemar, O. Lagerstedt, H. P. Gislason, J. Appl. Phys. 51, 625 (1980).

[95] K. Naniwae, S. Itoh, H. Amano, K. Itoh, K. Hiramatsu, I. Akasaki, J. Cryst. Growth 99, 381 (1990).

[96] T. Detchprochm, K. Hiramatsu, H. Amano, I. Akasaki, J. Appl. Phys. 61, 2688 (1992).

[97] R.J. Molnar, W. Götz, L.T. Romano, N.M. Johnson, J. Cryst. Growth 178, 147-156 (1997).

[98] H Lee, M Yuri, T Ueda, JS Harris, K Sin, J. Electron. Mater. 26, 898-902 (1997).

[99] T. Paskova, J. Birch, S. Tungasmita, R. Becard, M. Heuken, E. B. Svedberg, P. Runesson, E. M. Goldys, B. Monemar, Phys. Stat. Sol. A 176, 415 (1999).

[100] V. Wagner, O. Parillaud, H. J. Buhlmann, M. Ilegems, Phys. Stat. Sol. A 176, 429 (1999).

[101] P. R. Tavernier, E. V. Etzkorn, Y. Wang, D. R. Clarke, Appl. Phys. Lett. 77, 1804 (2000).

[102] S. Gu, R. Zhang, Y. Shi, Y. Zheng, L. Zhang, F. Dwikusuma, T. F. Kuech, J. Cryst. Growth 231, 342 (2001).

[103] M. Namerikawa, T. Sato, O. Takahashi, T. Suemasu, F. Hasegawa, J. Cryst. Growth 237-239, 1089 (2002).

[104] H. Murakami, Y. Kumagai, H. Seki, A. Koukitsu, J. Cryst. Growth 247, 245 (2003).

[105] Y. Golan, X. H. Wu, J. S. Speck, R. P. Vaudo, V. M. Phanse, Appl. Phys. Lett. 73, 3090 (1998).

[106] W. Zhang, T. Riemann, H. R. Alves, M. Heuken, D. Meister, W. Kriegseis, D. M. Hofmann, J. Christen, A. Krost, B. K. Meyer, J. Cryst. Growth 234, 616 (2002).

[107] T. Kawabata, T. Matsuda, S. Koide, J. Appl. Phys. 56, 2367 (1984).

[108] M. Hashimoto, H. Amano, N. Sawaki, I. Akasaki, J. Cryst. Growth 68, 163 (1984).

[109] C.-Y. Hwang, M. J. Schurman, W. E. Mayo, Y. Li, Y. Lu, H. Liu, T. Salagaj, R. A. Stall, J. Vac. Sci. Technol. A 13, 672-675 (1995).

[110] W. Van Der Stricht, I. Moerman, P. Demeester, J. A. Crawley, E. J. Thrush, P. G. Middleton, C. Trager-Cowan, K. P. O’Donnell, Mater. Res. Soc. Symp. Proc. 395, 231 (1996). 
[111] A. Estes Wickenden, D. K. Wickenden, T. J. Kistenmacher, J. Appl. Phys. 75, 5367-5371 (1994).

[112] J. C. Ramer, K. Zheng, C. F. Kranenberg, M. Banas, S. D. Hersee, Mater. Res. Soc. Symp. Proc. 395, 225 (1996).

[113] J. Han, T. -B. Ng, R. M. Biefeld, M. H. Crawford, D. M. Follstaedt, Appl. Phys. Lett. 71, 3114 (1997).

[114] C. F. Lin, G. C. Chi, M. S. Feng, J. D. Guo , J. S. Tsang, J. Minghuang Hong, Appl. Phys. Lett. 68, 3758-3760 (1996).

[115] L. Sugiura, K. Itaya, J. Nishio, H. Fujimoto, Y. Kokubun, J. Appl. Phys. 82, 4877 (1997).

[116] Y. Golan, P. Fini, S. P. DenBaars, J. S. Speck, Jpn. J. Appl. Phys. 37, 4695 (1998).

[117] M. Sumiya, T. Ohnishi, M. Tanaka, A. Ohtomo, M. Kawasaki, M. Yoshimoto, K. Koinuma, K. Ohtsuka, S. Fuke, MRS Internet J. Nitride Semicond. Res. 4S1, G6.23 (1999).

[118] H. Yamane, M. Shimada, T. Endo, F. J. DiSalvo, Jpn. J. Appl. Phys. 37, 3436 (1998).

[119] M. Sumiya, N. Ogusu, Y. Yotsuda, M. Itoh, S. Fuke, T. Nakamura, S. Mochizuki, T. Sano, S. Kamiyama, H. Amano, I. Akasaki, J. Appl. Phys. 93, 1311 (2003).

[120] M. Sumiya, K. Yoshimura, N. Ogusu, S. Fuke, K. Mizuno, M. Yoshimoto, L. T. Romano, J. Vac. Sci. Technol. 20, 456 (2002).

[121] XW Wu, LM Brown, D Kapolnek, S Keller, B Keller, SP DenBaars, JS Speck, J. Appl. Phys. 80, 3228-3237 (1996).

[122]This was also confirmed by Tusda et al., the $5^{\text {th }}$ International Conference on Nitride Semiconductors, Nara, Japan. Technical digest Th-P03.013 (2003)

[123]S. Sato, S. Ogawa, K. Ohtsuka, N. Kuwahara, M. Sumiya, Y. Takano, and S. Fuke, Extended Abstracts (the $61^{\text {st }}$ Autumn Meeting 2000) The Japan Society of Applied Physics, 7a-H-1

[124]H. Amano, and I. Akasaki, Oyo Buturi 68, 768 (1999)

[125] Y. Kobayashi, T. Akasaka, N. Kobayashi, Jpn. J. Appl. Phys. 37, L1208 (1998).

[126] T. Ito, M. Sumiya, Y. Takano, K. Ohtsuka, S. Fuke, Jpn. J. Appl. Phys. 38, 649 (1999).

[127] T. Ito, K. Ohtsuka, K. Kuwahara, M. Sumiya, Y. Takano, S. Fuke, J. Cryst. Growth 205, 20 (1999).

[128] J. L. Weyher, P. D. Brown, A. R. A. Zauner, S. Muller, C. B. Boothroyd, D. T. Foord, P. R. Hageman, C. J. Humphreys, P. K. Larsen, I. Grezegory, S. Porowski, J. Cryst. Growth 204, 419 (1999).

[129] M. Sumiya, K. Yoshimura, T. Ito, K. Ohtsuka, S. Fuke, K. Mizuno, M. Yoshimoto, H. Koinuma, A. Ohtomo, M. Kawasaki, J. Appl. Phys. 88, 1158 (2000).

[130]M. Sumiya, and S. Fuke, Oyo Buturi 70, 178 (2001)

[131]"Growth of GaN layer on $6 \mathrm{H}-\mathrm{SiC}$ substrates using a GaN buffer layer", M. Kurumasa, T. Ito, k. Ohtsuka, N. Kuwahara, M. Sumiya, Y. Takano, and S. Fuke, Technical Report of IEICE ED99-45, 31 (1999)

[132]Y. Matsuura, T. Ochi, M. Sumiya, and S. Fuke, submitted to Jpn. J. Appl. Phys

[133] M. Sumiya, T. Chikyow, T. Sasahara, K. Yoshimura, J. Ohta, H. Fujioka, S. Tagaya, H. Ikeya, H. Koinuma, S. Fuke, Jpn. J. Appl. Phys. 41, 5038 (2002).
[134] T. Matsuoka, T. Ishi, Proc. Int. Workshop on Nitride Semiconductors, 1,11 (2000).

[135] H. Morkoc, A. Di Carlo, R. Cingolani, Sol. St. Electr. 46, 157 (2002).

[136] O. Ambacher, J. Smart, J. R. Shealy, N. G. Weimann, K. Chu, M. Murphy, W. J. Schaff, L. F. Eastman, R. Dimitrov, L. Wittmer, M. Stutzmann, W. Rieger, J. Hilsenbeck, J. Appl. Phys. 85, 3222 (1999).

[137] M. Sumiya, K. Yoshimura, K. Ohtsuka, S. Fuke, Appl. Phys. Lett. 76, 2098 (2000).

[138] T. K. Zywietz, J. Neugebauer, M. Scheffler, Appl. Phys. Lett. 74, 1695 (1999).

[139] L. K. Li, M. J. Jukovic, W. I. Wang, J. M. Van Hove, P. P. Chow, Appl. Phys. Lett. 76, 1740 (2000).

[140] A. J. Ptak, H. Myers, L. T. Romano, C. G. Van de Walle, J. E. Northrup, Appl. Phys. Lett. 78, 285 (2001).

[141] H. M. Ng, A. Y. Cho, J. Vac. Sci. Technol. B 20, 1217 (2002).

[142] E. Frayssinet, W. Knap, P. Prystawko, M. Leszczynski, I. Grezegory, T. Suski, B. Beaumount, P. Gibart, J. Cryst. Growth 218, 161 (2000).

[143] E. S. Hellman, D. N. E. Buchanan, D. Wiesmann, I. Brener, MRS Internet J. Nitride Semicond. Res. 1, 16 (1996).

[144] S. F. Chichibu, A. Setoguchi, A. Uedono, K. Yoshimura, M. Sumiya, Appl. Phys. Lett. 78, 28 (2001).

[145] I. Gorczyca, A. Svane, N. E. Christensen, Sol. St. Comm. 101, 747-752 (1997).

[146] A. Uedono, S. F. Chichibu, Z. Q. Chen, M. Sumiya, R. Suzuki, T. Ohdaira, T. Mikado, T. Mukai, S. Nakamura, J. Appl. Phys. 90, 181 (2001).

[147] K. A. Rickert, A. B. Ellis, J. K. Kim, J. L. Lee, F. J. Himpsel, F. Dwikusuma, T. F. Kuech, J. Appl. Phys. 92, 6671 (2002).

[148] B. P. Luther, J. M. DeLucca, S . E. Mohney, R. F. Karlicek, Appl. Phys. Lett. 71, 3859 (1997).

[149] J. S. Kwak, K. Y. Lee, J. Y. Han, J. Cho, S. Chae, O. H. Nam, Y. Park, Appl. Phys. Lett. 79, 3254 (2001).

[150] T. Gessmann, Y. -L. Li, E. L. Waldron, J. W. Graff, E. F. Schubert, Appl. Phys. Lett. 80, 986 (2002).

[151] T. Gessmann, J. W. Graff, Y. -L. Li, E. L. Waldron, E. F. Schubert, J. Appl. Phys. 92, 3740 (2002).

[152] B. K. Ridley, Appl. Phys. Lett. 77, 990 (2000).

[153] Y. J. Lin, Z. L. Wang, H. C. Chang, Appl. Phys. Lett. 81, 5183 (2002).

[154] T. Hashizume, R. Nakazaki, Appl. Phys. Lett. 80, 4564 (2002).

[155] C. I. Wu, A. Khan, Appl. Phys. Lett. 74, 1433 (1999).

[156] C. I. Wu, A. Khan, J. Appl. Phys. 86, 3209 (1999).

[157] Y. Nanishi, Y. Saito, T. Yamaguchi, Jpn. J. Appl. Phys. 42, 2549 (2003).

[158] K. Xu, A. Yoshikawa, Appl. Phys. Lett. 83, 251 (2003).

[159]T. Matsuoka et al. Extended Abstracts (the $64^{\text {th }}$ Autumn meeting 2003) The Japan Society of Applied Physics, 31a-G-9 [160]M. Takabe, M. Sumiya, and S. Fuke, Extended Abstracts (the $64^{\text {th }}$ Autumn meeting 2003) The Japan Society of Applied Physics, 1p-G-5 


\section{FIGURES}

(a) $+\mathrm{C} \mathrm{GaN}$

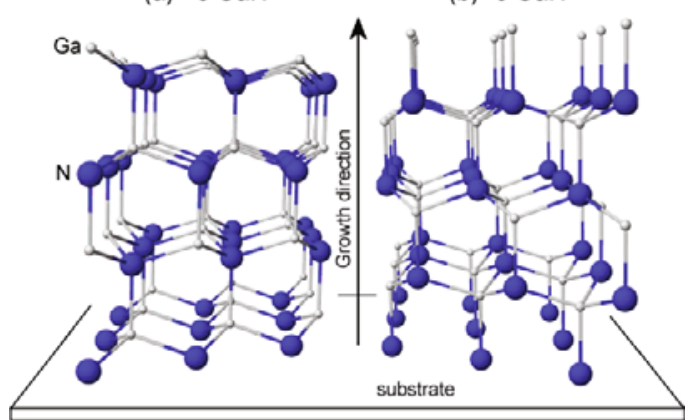

Figure 1. Schematic illustration of GaN wurtzite crystal structure exhibiting the polarity along the c-axis. The small and large spheres indicate $\mathrm{Ga}$ and $\mathrm{N}$, respectively. $\mathrm{GaN}$ with $\mathrm{Ga}-$ face $(+\mathrm{c})$ polarity on left side and $\mathrm{GaN}$ with $\mathrm{N}$-face $(-\mathrm{c})$ polarity on right side. When the direction of the three bonds of the IIIelement is towards the substrate, the polar structure is defended as $+\mathrm{c}$ polarity. On the other hand, when that of the bonds is upward against substrate, it is defined as having $-c$ polarity. The termination element on the surface is not specified unless it is explicitly mentioned in this article.

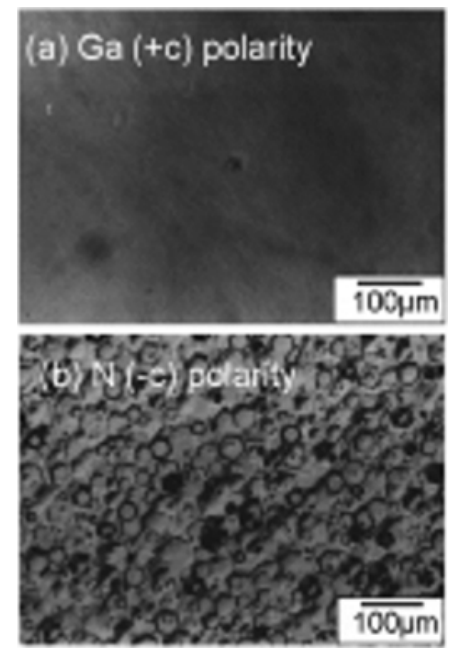

Figure 2. Optical microscope images of (a) $+\mathrm{c} G a N$ and (b) $-\mathrm{c}$ GaN films on sapphire substrates. The surface morphology of typical $+\mathrm{c}$ and $-\mathrm{c}$ GaN films are smooth and hexagonal facetted, respectively. The polarity was determined by the CAICISS method described in Sec. 2.4.

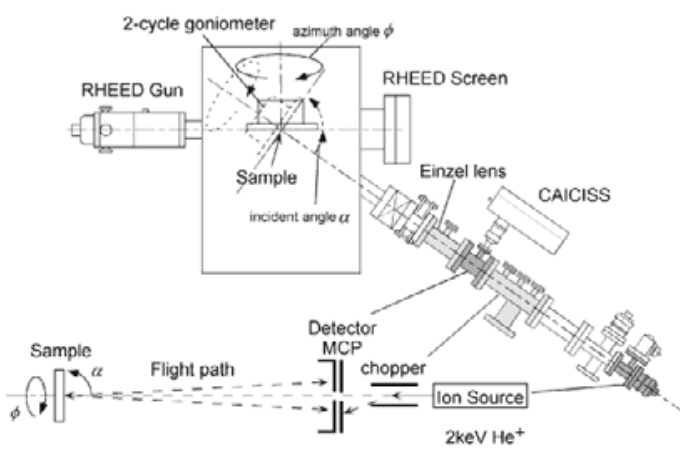

Figure 3. Schematic illustration of CAICISS apparatus with a chamber and block diagram. The incident and azimuth angles of the ion beam can be altered by moving the sample holder, which is equipped with a heater.

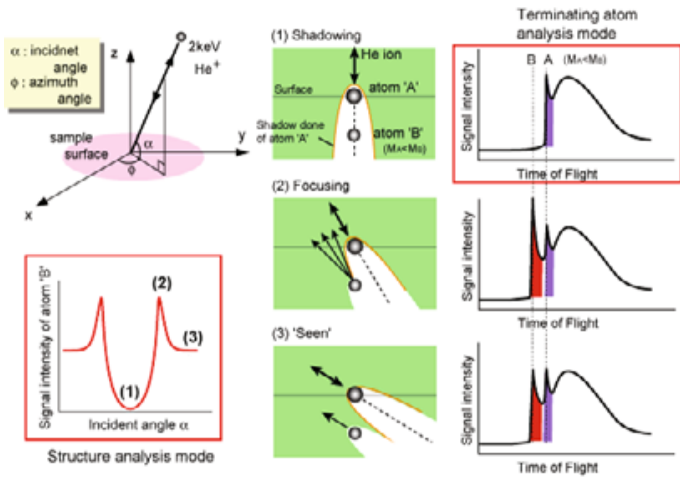

Figure 4. Schematic illustration explaining the focusing and shadowing effect. According to the definition given in Ref. [5], which was made by Katayama et al., the incident angle $\alpha$ was changed from $90^{\circ}$ (normal to the sample surface) towards the lower angle. The angular dependence of the CAICISS signal can be obtained because both effects correspond to the atomic arrangement on surface, as observed in the middle. Variations in the TOF spectra are induced by changing the incident angle, as shown on the right. The dependence of the integrated peak (colored area) of the TOF spectra on the angle corresponds to the CAICISS result shown on the bottom of the left-hand side, which can be used to determine the polarity and the surface structure. 


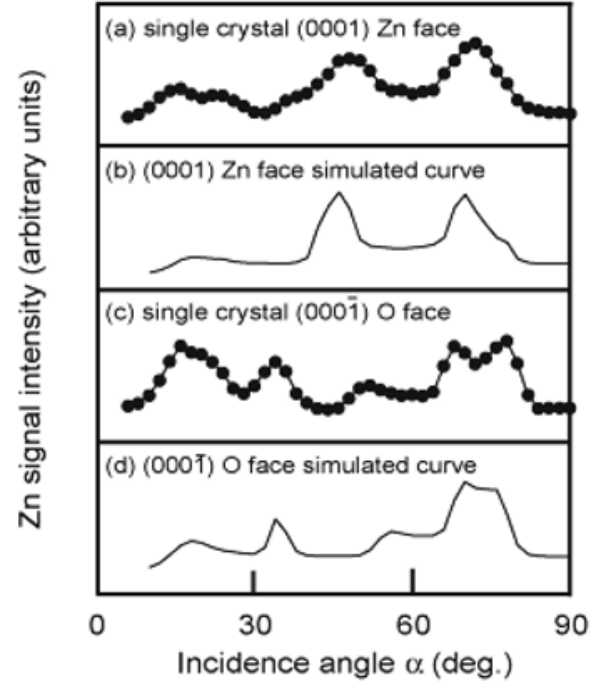

Figure 5. Incident angular dependence of the $\mathrm{Zn}$ signal intensity when the specimen was tilted along the $<110>$ azimuth. (a) single crystal (0001) Zn face $(+\mathrm{c})$, (b) simulated curve of (a), (c) single crystal (0001)O-face (-c), and (d) simulated curve of (c). Simulation was based on a threedimensional two-atom model for a virtual surface cut from an ideal bulk structure without any reconstruction. (Ohnishi Dr. Thesis p.70 Ref. [49]) The polarity of the GaN was determined from the angular dependence revealed by CAICISS by comparing these results with these results of $\mathrm{ZnO}$, because $\mathrm{ZnO}$ has the same crystal structure and lattice constants that are very close to those of GaN.

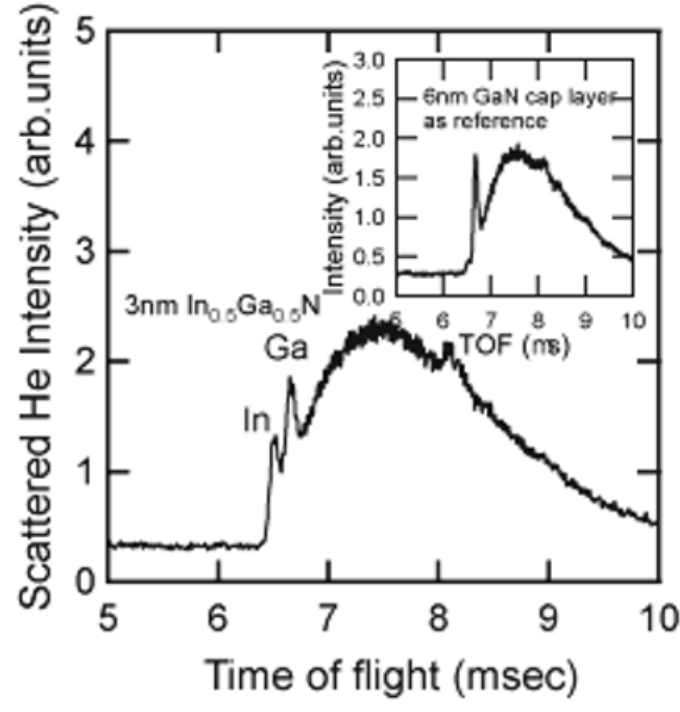

Figure 6. TOF spectrum of the backscattered $\mathrm{He}^{+}$ions used in the CAICISS analysis of an $\operatorname{In}_{0.5} \mathrm{Ga}_{0.5}$ SQW when the ion beam was irradiated at normal incidence to the sample. The inset depicts the TOF spectrum for $\operatorname{In}_{0.2} \mathrm{Ga}_{0.8} \mathrm{~N}$ capped with 6-nmthick $\mathrm{GaN}$ as a reference [after Ref. 51]. The In and Ga signals can be detected separately for each time-of-flight. The inset indicates how CAICISS analysis detects a region several $\mathrm{nm}$ deep below the surface.

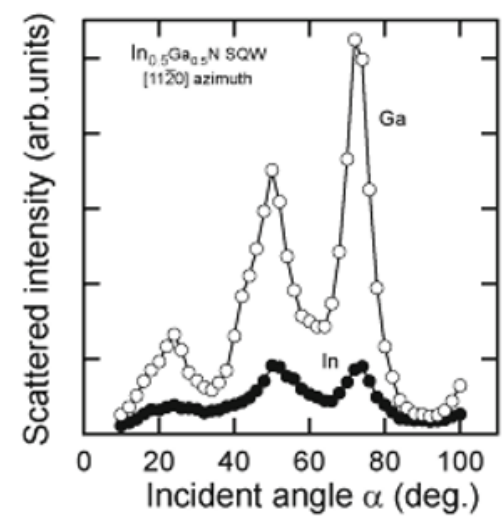

Figure 7. Incident angle dependence of $\mathrm{Ga}$ and In scattered intensity at the $[11 \overline{2} 0]$ azimuth for $\operatorname{In}_{0.5} \mathrm{Ga}_{0.5} \mathrm{~N}$ SQW. Variation of both the $\mathrm{Ga}$ and In signals indicates $+\mathrm{c}$ polarity judging from the CAICISS results on $\mathrm{ZnO}$ bulk given in Fig. 5. Indium atoms incorporated into an $\operatorname{In}_{\mathrm{x}} \mathrm{Ga}_{1-\mathrm{x}} \mathrm{N}$ SQW were found to occupy substitutional Ga sites. [52]] 


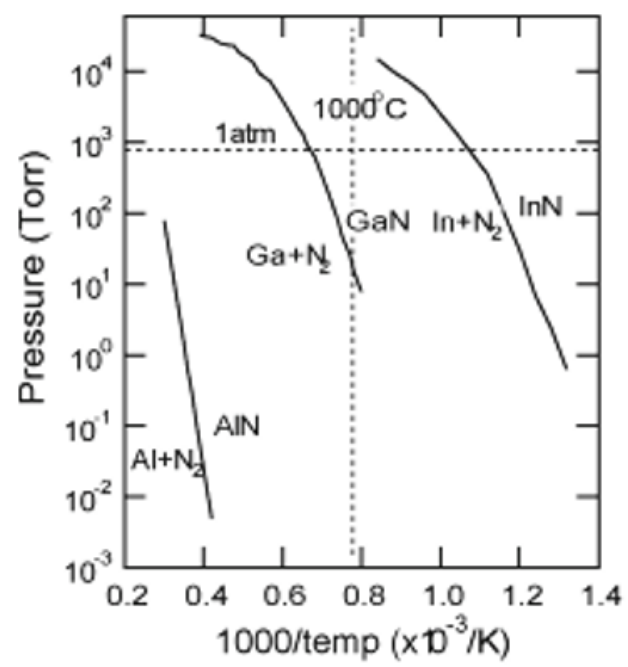

Figure 8. Equilibrium $\mathrm{N}_{2}$ pressure over III-V nitrides (solid) + III-metal (liquid). Lines for each nitride material are plotted together from Ref. 81

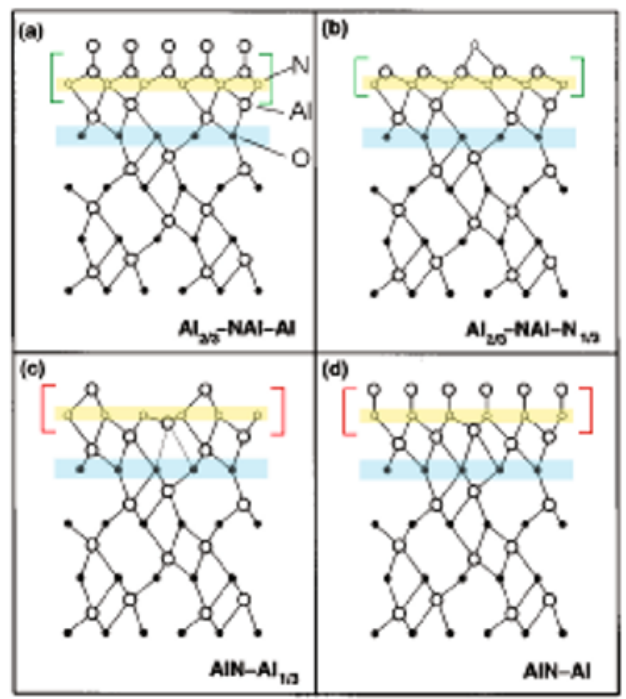

Figure 9. Models for the AlN thin films on c-plane sapphire substrates given in Ref. [58]. The color regions are added to explain the theoretical predictions. The structures in the brackets correspond to the polar structures of AlN described in Ref. [84]. (a) and (b) correspond to a $+c$ polar surface. (c) and (d) to - c polarity.

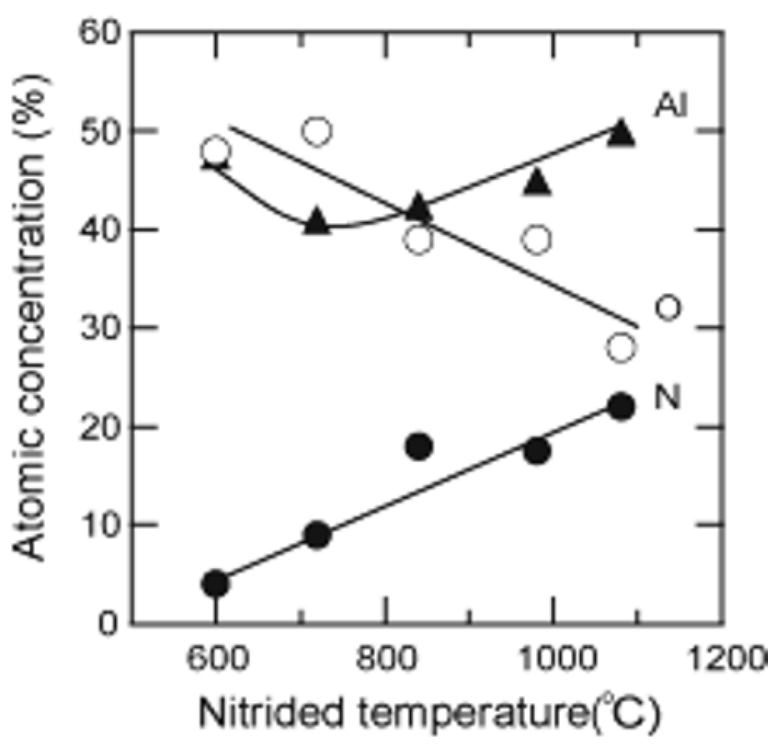

Figure 10. Nitridation-temperature dependence of the atomic concentration on a sapphire surface determined by XPS analysis. When HT-GaN films were deposited on sapphire substrates nitrided at temperatures of more than $700^{\circ} \mathrm{C}$, the films represented $-\mathrm{c}$ polarity and hexagonal facetted surfaces.

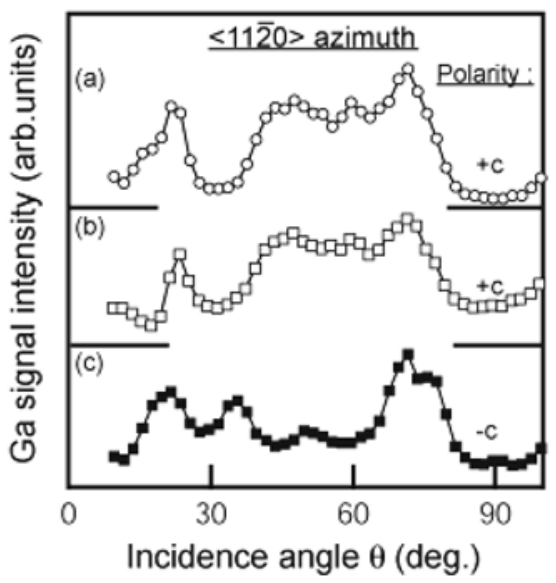

Figure 11. Angular dependence of Ga signal intensity for the buffer layers in CAICISS analysis: (a) as-deposited 20-nm buffer layer on non-nitrided sapphire, (b) as-deposited 20-nm buffer layer on nitirided sapphire and (C) annealed buffer layer of (b). The polarity of a buffer layers on nitrided sapphire substrates changed from $+\mathrm{c}$ to $-\mathrm{c}$ polarity, while there was no change for buffer layers on non-nitrided sapphire substrates. [after Ref. 35]. This is the first determination of the polarity for LT-GaN buffer layers, which has led to an understanding of the correlation between the MOCVD process and the polarity. 


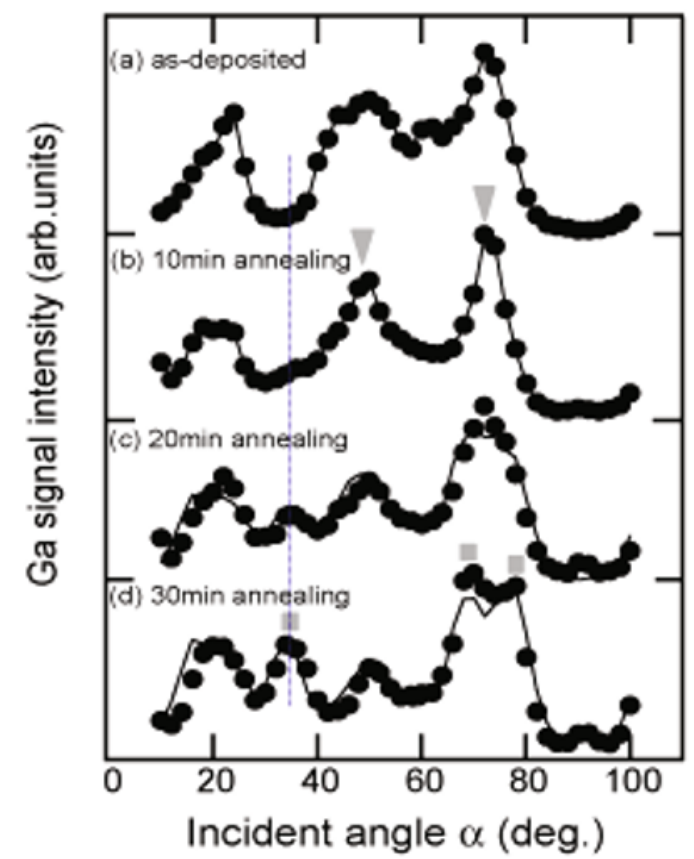

Figure 12. Incident angular dependence of Ga signal intensity at $[11 \overline{2} 0]$ azimuth of $\mathrm{He}^{+}$beam in CAICISS analysis for a $210 \mathrm{~nm} \mathrm{GaN}$ buffer layer on nitrided sapphire: (a) as-deposited, (b) $10 \mathrm{~min}$, (c) $20 \mathrm{~min}$, and (d) $30 \mathrm{~min}$ annealing time. The lines in (c) and (d) are calculated according to the weight ratios of the $+\mathrm{c}$-c polarity material as being $5: 5$ and $2: 8$, respectively, assuming that they are of the same crystal quality i.e., the same intensity of CAICISS signal for $+\mathrm{c}$ and $-\mathrm{c}$ domains. The sharpening peak in (b) indicates crystallization, and the peak splitting at $72^{\circ}$ in (c) suggests the existence of -c domains that are becoming exposed due to the evaporation of the buffer layer. [after Ref. 118] 

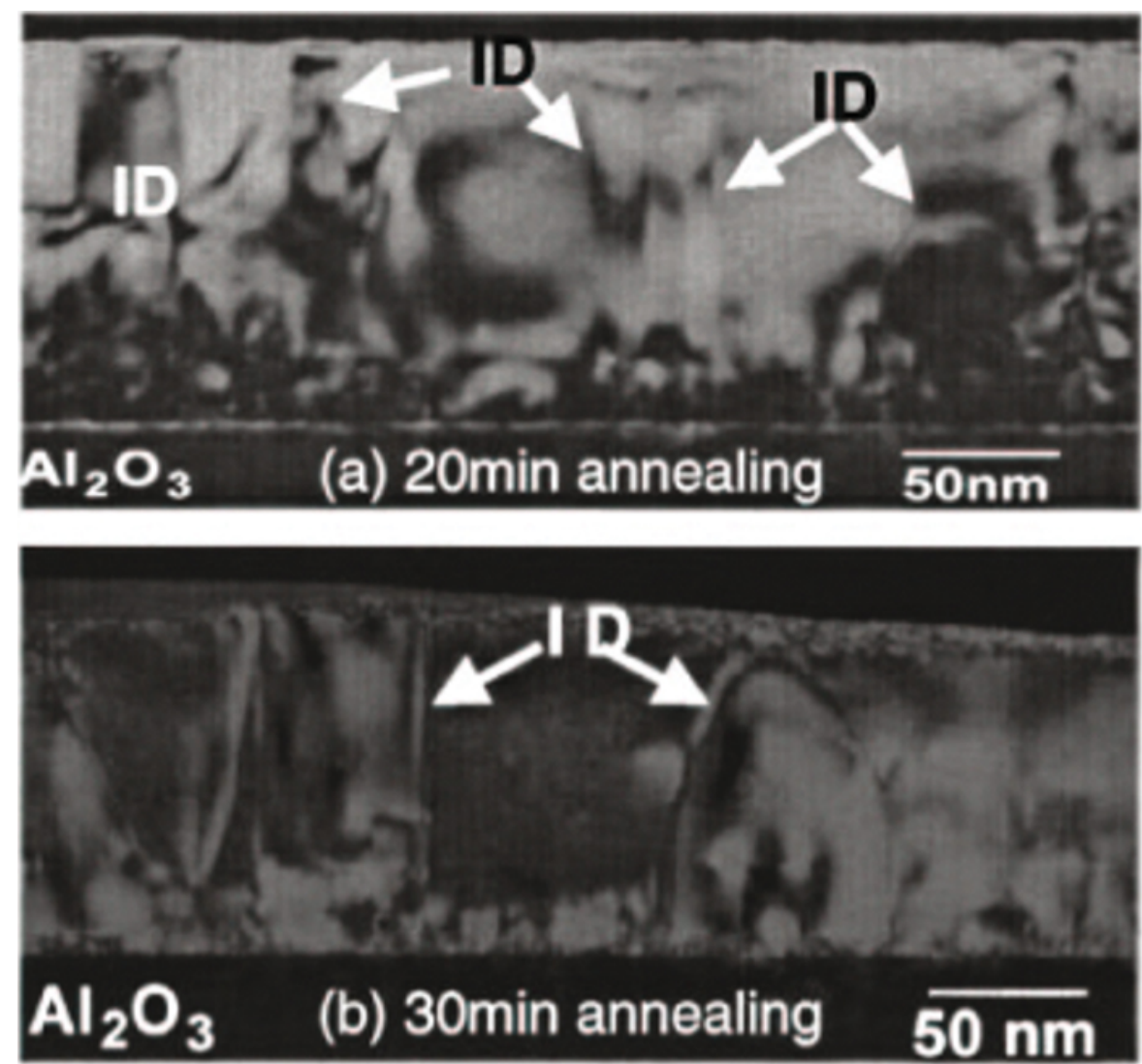

Figure 13. Cross-sectional TEM images for the buffer layers annealed for (a) 20min and (b) 30min. The samples correspond to (c) and (d) in Figure 12, respectively. [after Ref. 118 ] 


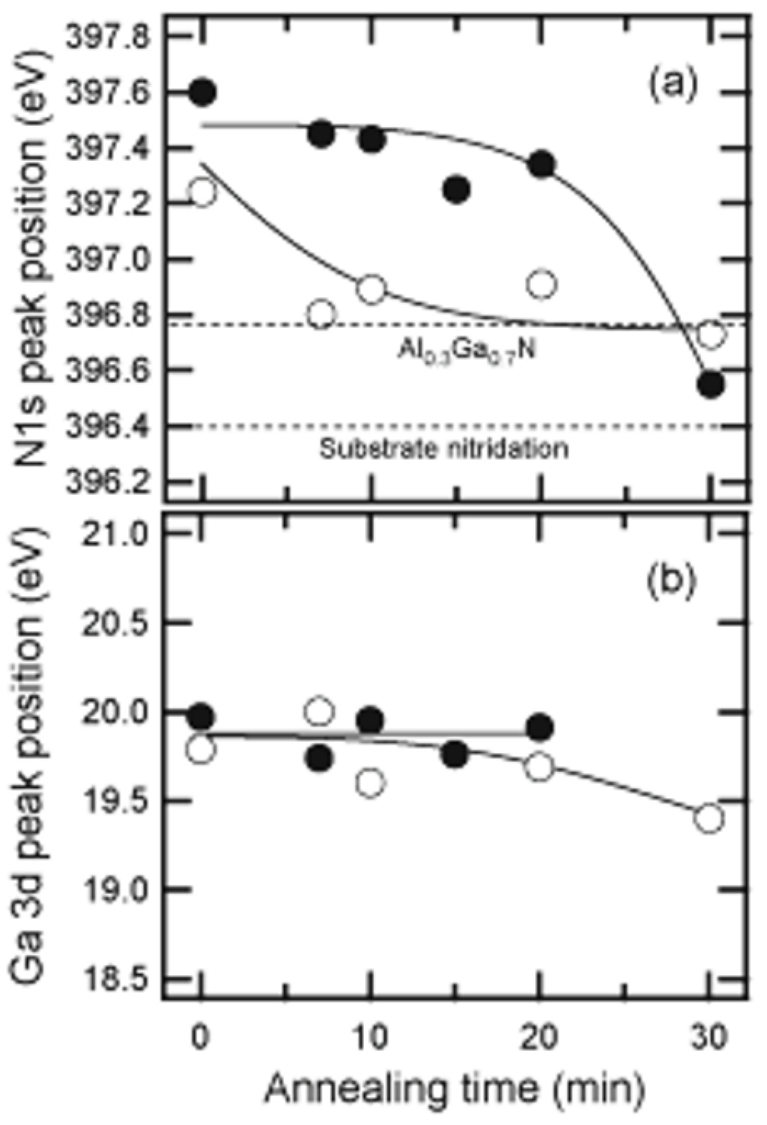

Figure 14. Dependence of (a) N1s and (b) Ga 3d peak positions for a 20-nm-thickness $\mathrm{GaN}$ buffer layer on $\mathrm{H}_{2}$ cleaned (open circles) and nitrided (closed circles) sapphire substrates on the annealing time under the $\mathrm{N}_{2}$ and $\mathrm{H}_{2}$ mixed ambient. The positions were detected by XPS analysis. [after Ref. 117 ] The sample on the nitrided substrate evaporated completely, and $\mathrm{AlGaN}$ was formed at the interface between the sample and the non-nitrided substrate.

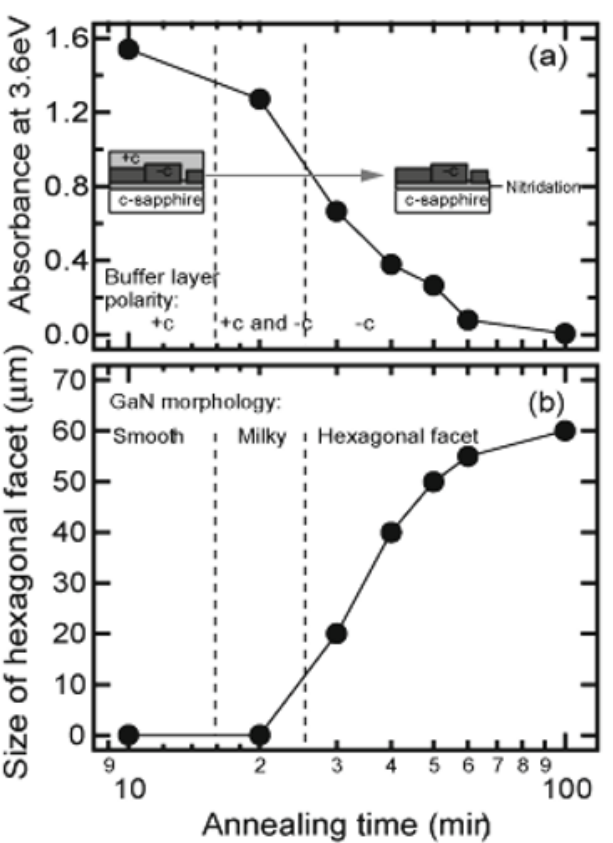

Figure 15. (a) Dependence of absorbance at $3.6 \mathrm{eV}$ on annealing time for a $160 \mathrm{~nm} \mathrm{GaN}$ buffer layer on a nitrided sapphire substrate. (b) Variation of hexagonal facet size of GaN films deposited on annealed buffer layers in (a). The polarities of the HT-GaN layers are attributed to those of the annealed buffer layers. [after Ref. 35 ]

\section{(a) V/III 20000 on nitrided sapphire}

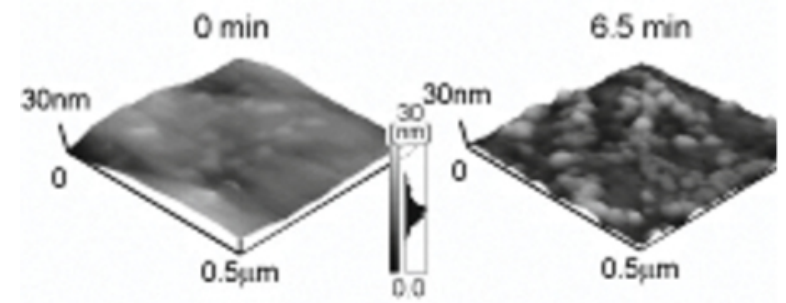

(b) V/III 2000 on nitrided sapphire

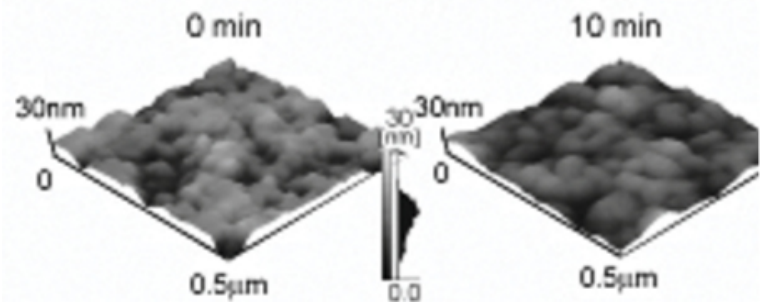

Figure 16. AFM images of annealed buffer layers on nitrided sapphire substrates before (on the left) and after (on the right) dipping in $\mathrm{KOH}$ solution for each time stated. (a) The sample deposited under a V/III ration of 20000 and annealed in the $\mathrm{H}_{2}$ and $\mathrm{N}_{2}$ mixed ambient for $20 \mathrm{~min}$, and (b) the sample deposited under a V/III ratio of 5000 and annealed in an $\mathrm{N}_{2}$ ambient for 20min. [after Ref. 117] 


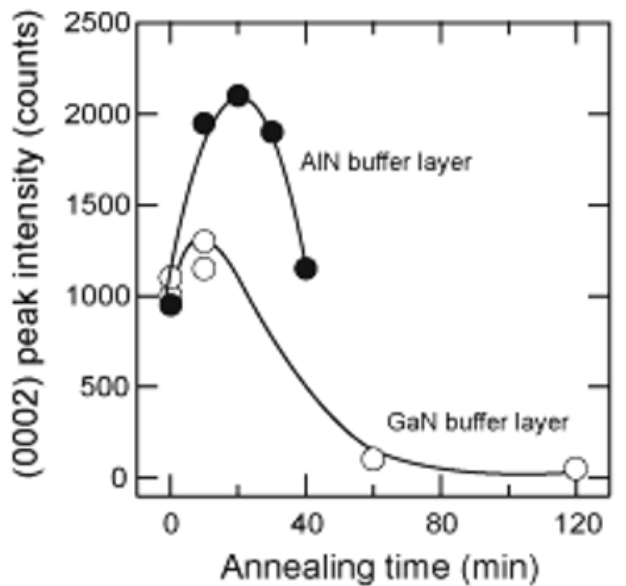

Figure 17. Variation of (0002) peak intensity of LT-GaN (open circles) and AIN (closed circles) buffer layers of $20 \mathrm{~nm}$ thickness as a function of annealing time. The intensity was enhanced due to the crystallization of the samples induced by the annealing, and it subsequently decreased due to the layer being thinned by sublimation. This indicates that the effects of mass transportation and sublimation are smaller for AlN buffer layers.

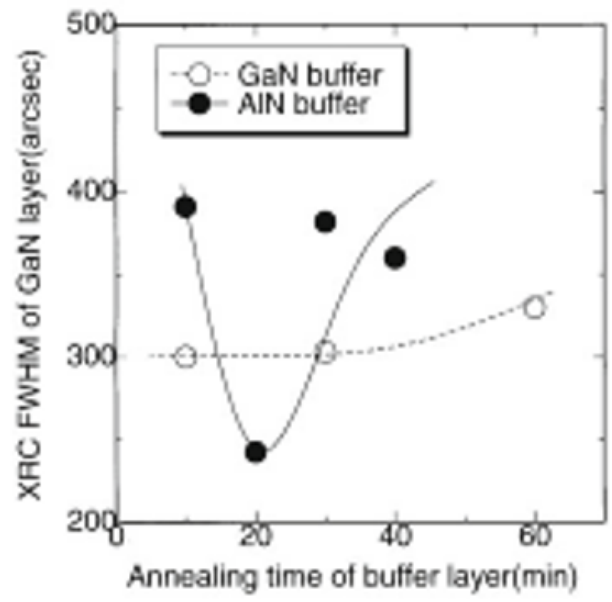

Figure 18. FWHM of $\omega$ (0002) for HT-GaN films deposited on GaN (open circles) and AlN (closed circles) buffer layers with the same thickness, when the buffer layers were annealed for the times shown in the figure. The conditions for obtaining better quality HT-GaN material are wider with $\mathrm{GaN}$ buffer layers [127]].

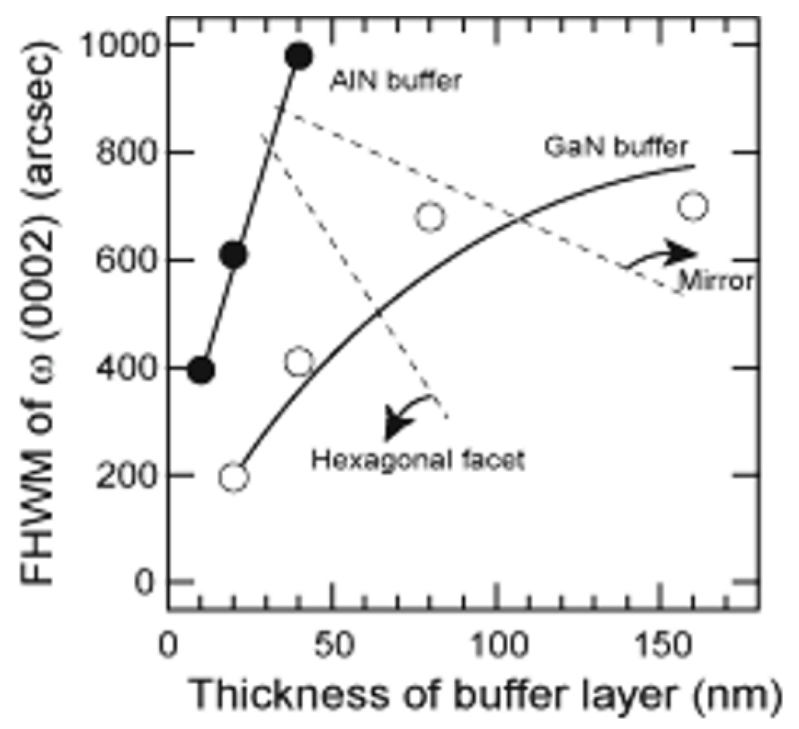

Figure 19. The FWHM value of $\omega(0002)$ for $1 \mu \mathrm{m}$ HT-GaN films deposited on AlN (closed circles) and GaN (open circles) buffer layers with the thicknesses in the figure. The buffer layers were annealed for $10 \mathrm{~min}$ under the optimum ambient. Their polarity changed as indicated by the surface morphology, and the polarity conversion occurred drastically in the case of the AlN buffer layer.
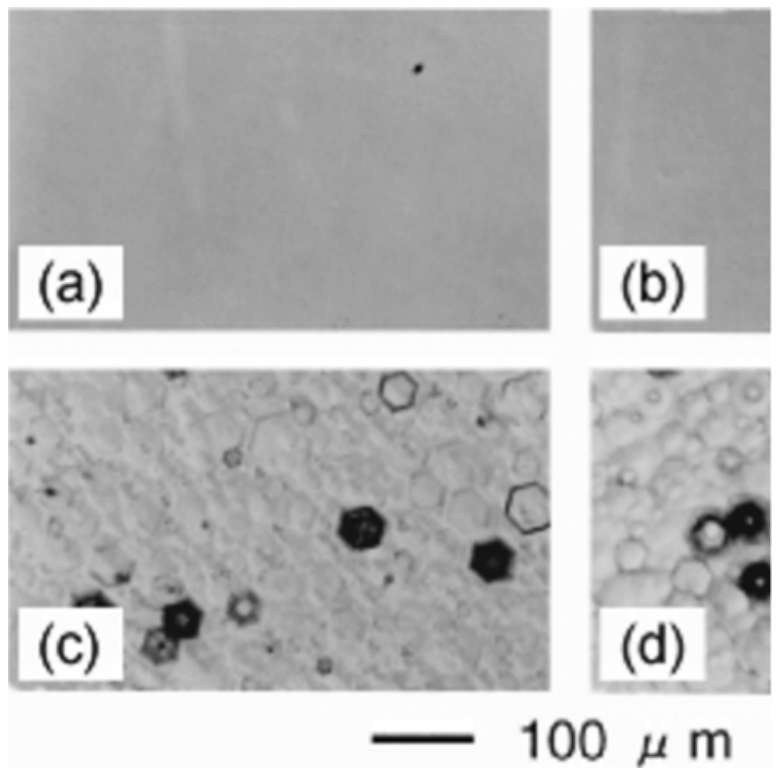

Figure 20. Influence on surface morphology of HT-GaN films of the V/III ratio in AlN buffer layers deposited at $1040{ }^{\circ} \mathrm{C} ; \mathrm{V} /$ III ratio= (a) 600, (b) 1800, (c) 6800, and (d) 13700. [127] ] A lower $\mathrm{V} / \mathrm{III}$ ratio was required for the deposition of AIN buffer layer in order to obtain $+\mathrm{c} \mathrm{GaN}$ film. 


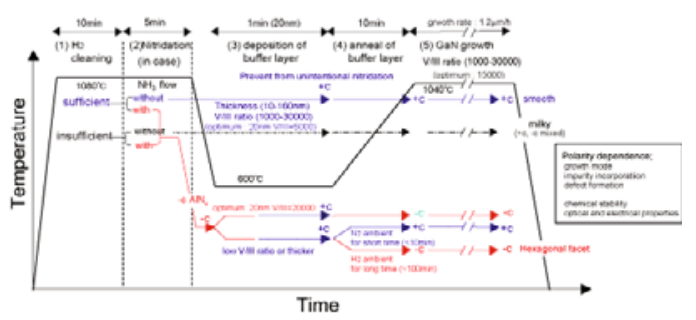

Figure 21. Summary of the key points for controlling the polarity of GaN films on sapphire substrates (as detailed in the Articles and the Recipes) in the time chart of the two-step MOCVD process. Our typical growth conditions are represented. The polarity at the end of each process is remarked with blue and red indicating $+\mathrm{c}$ and $-\mathrm{c}$ polarity, respectively, which can be used as the road map to control the polarity of GaN in MOCVD. [after Ref. 128]
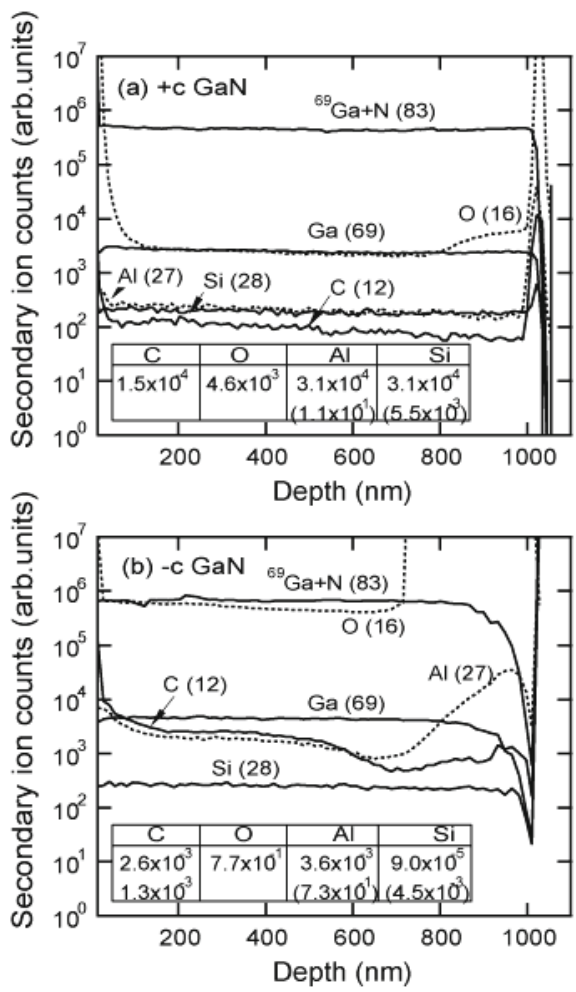

Figure 22. Depth profiles of $\mathrm{C}^{-}, \mathrm{O}^{-}, \mathrm{Al}^{-}, \mathrm{Si}^{-}, \mathrm{Ga}^{-}$and $\mathrm{GaN}^{-}$for (a) $+\mathrm{c}$ GaN and (b) $-\mathrm{c}$ GaN films of $1 \mu \mathrm{m}$ in thickness. The intensities of impurities normalized to the $\mathrm{GaN}^{-}$count are listed at the bottom of each figure. The values normalized to the $\mathrm{Ga}+\mathrm{Ga}^{+}$ion in the brackets are evaluated from depth profiles using and $\mathrm{O}_{2}{ }^{+}$primary beam [after Ref. 135]. The Al, $\mathrm{C}$ and $\mathrm{O}$ impurities were more readily incorporated into $-\mathrm{c}$ GaN films.

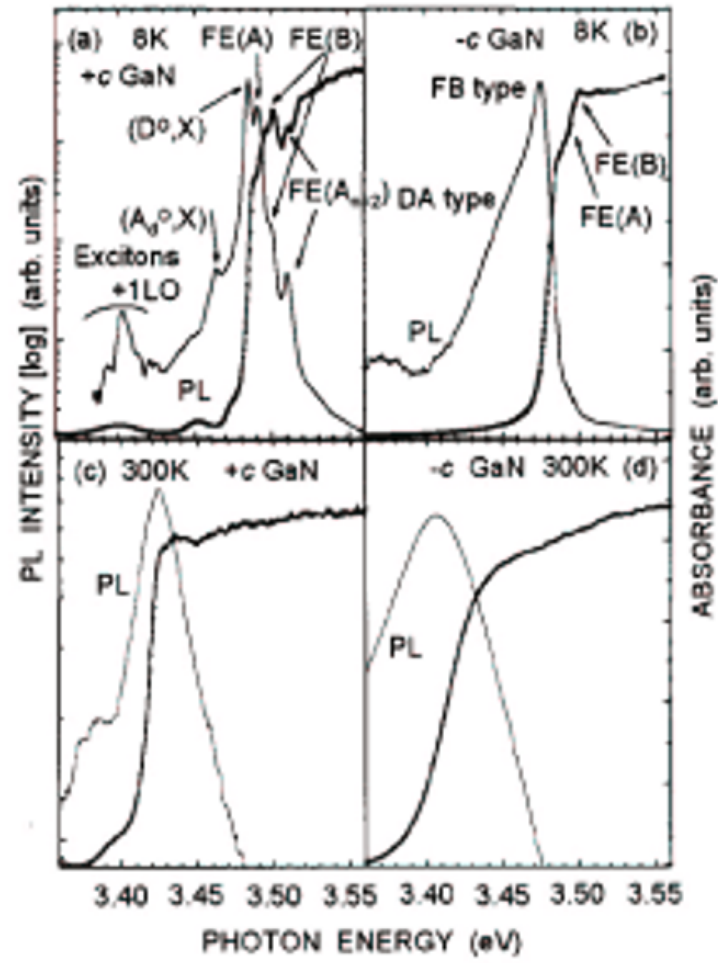

Figure 23. Comparison of PL and OA spectra at $8 \mathrm{~K}$ and $300 \mathrm{~K}$ for $+\mathrm{c}$ and $-\mathrm{c} \mathrm{GaN}$ films. [after Ref. 142 ]

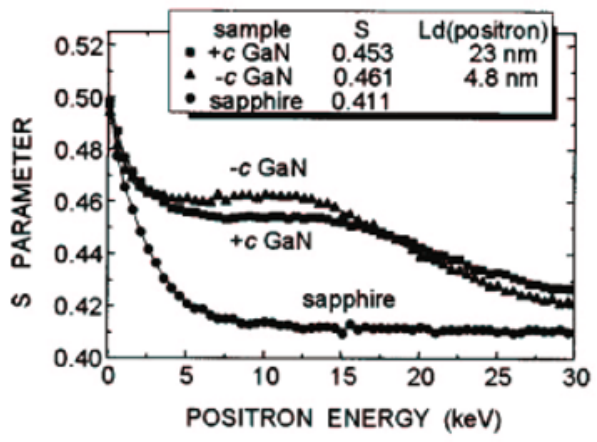

Figure 24. The line shape parameter $\mathrm{S}$ of $+\mathrm{c}$ and $-\mathrm{c} \mathrm{GaN}$ as a function of the position of the acceleration energy $\mathrm{E}$. The value of S depends on the size and density of vacancy-type defects. The diffusion length of positrons decreases with increasing defect density. [after Ref. 142] 


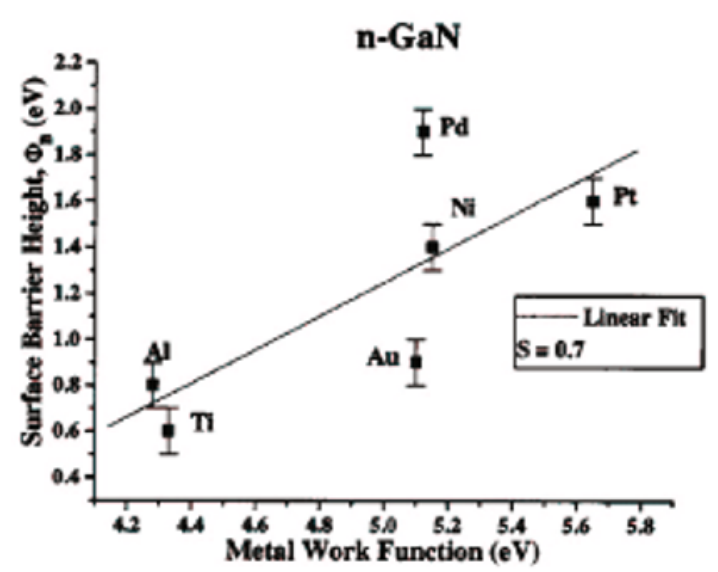

Figure 25a. Surface barrier heights measured in Ref. [147] for $\mathrm{n}-\mathrm{GaN}$ shown as a function of the work function of the metal used for the contact formation.

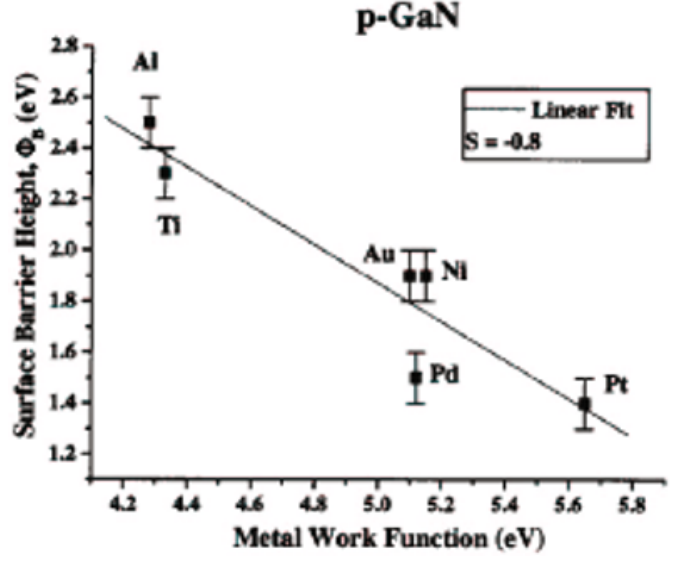

Figure 25b. Surface barrier heights measured in Ref. [147] for $\mathrm{p}-\mathrm{GaN}$ shown as a function of the work function of the metal used for the contact formation. 


\section{TABLES}

Table Ia. List of techniques for evaluating GaN polarity in chronological order. The relationship between growth conditions and the resulting polarity is also represented.

\begin{tabular}{|c|c|c|c|c|c|}
\hline Year & $\begin{array}{c}\text { Who [Ref] } \\
\text { (growth method) }\end{array}$ & Substrate or buffer layer & $\begin{array}{c}\text { Process or Feature of } \\
\text { HT-GaN }\end{array}$ & Method (probe) & polarity \\
\hline \multirow[t]{2}{*}{88} & \multirow{2}{*}{$\begin{array}{l}\text { Sasaki [12] } \\
\text { (LP-MOCVD) }\end{array}$} & Si-SiC & Smooth surface & \multirow{2}{*}{$\begin{array}{c}\text { XPS } \\
\text { (photoelectron) }\end{array}$} & $-\mathrm{C}$ \\
\hline & & C-SiC & Rough surface & & $+\mathrm{C}$ \\
\hline \multirow[t]{3}{*}{94} & \multirow{3}{*}{$\begin{array}{l}\text { Sun [15] } \\
\text { (MOCVD) }\end{array}$} & c-sapphire & Hexagonal & \multirow{3}{*}{$\begin{array}{l}\text { Chemical stability } \\
\left(\mathrm{H}_{2} \text { annealing }\right)\end{array}$} & $+\mathrm{C}$ \\
\hline & & M-sapphire & Ridgelike & & \\
\hline & & Si-SiC & Hexagonal & & $-\mathrm{C}$ \\
\hline \multirow[t]{3}{*}{96} & \multirow{3}{*}{$\begin{array}{l}\text { Ponce [18] } \\
\text { (MOCVD) }\end{array}$} & Bulk Ga Smooth & \multirow{2}{*}{$\begin{array}{l}\text { Homo-epitaxy of HT- } \\
\text { GaN }\end{array}$} & \multirow{3}{*}{$\begin{array}{c}\text { CBED } \\
\text { (e-beam) }\end{array}$} & $+\mathrm{C}$ \\
\hline & & Bulk Ga $\quad$ Rough & & & $-\mathrm{C}$ \\
\hline & & Sapphire & Smooth surface & & $+C$ \\
\hline \multirow[t]{2}{*}{96} & \multirow{2}{*}{$\begin{array}{c}\text { Liliental-Weber } \\
\text { [19] }\end{array}$} & & Bulk GaN Smooth & \multirow[t]{2}{*}{ CBED } & $+\mathrm{C}$ \\
\hline & & & Rough & & $-\mathrm{C}$ \\
\hline \multirow[t]{3}{*}{96} & $\begin{array}{l}\text { Romano [20] } \\
\text { (MBE) }\end{array}$ & Nitride c- sapphire & & \multirow[t]{3}{*}{ CBED } & $-\mathrm{C}$ \\
\hline & (MOCVD) & c-sapphire & & & $+\mathrm{C}$ \\
\hline & (HVPE) & c-sapphire(ZnO buffer) & & & $+\mathrm{C}$ \\
\hline \multirow[t]{3}{*}{96} & \multirow[t]{3}{*}{$\begin{array}{l}\text { Rouviere [21] } \\
\text { (MOCVD) }\end{array}$} & \multirow{3}{*}{$\begin{array}{c}\text { a,C-sapphire } \\
(\text { GaN600 } \mathrm{C}+\text { no } \\
\text { anneal) } \\
\text { a,C-sapphire (AIN } \\
\left.800^{\circ} \mathrm{C}+1000^{\circ} \mathrm{C}\right)\end{array}$} & $\begin{array}{c}\text { Hexagonal }\left(1150^{\circ} \mathrm{C}\right. \\
\text { growth) }\end{array}$ & \multirow[t]{3}{*}{ CBED } & $-\mathrm{C}$ \\
\hline & & & Smooth $\left(950^{\circ} \mathrm{C}\right.$ growth) & & $+\mathrm{C}$ \\
\hline & & & Smooth $\left(900^{\circ} \mathrm{C}\right.$ growth) & & $+\mathrm{C}$ \\
\hline \multirow[t]{2}{*}{96} & \multirow[t]{2}{*}{$\begin{array}{l}\text { Daudin [45] } \\
\text { (MOCVD) }\end{array}$} & $\begin{array}{c}\text { GaN buffer layer } \\
\text { deposited on sapphire } \\
\text { at } 500^{\circ} \mathrm{C}\end{array}$ & $\begin{array}{c}\text { Smooth } \\
\text { (Both LT-layers were } \\
\text { annealed in } \mathrm{N}_{2} \text { at } \\
1000^{\circ} \mathrm{C} \text { for } 5 \mathrm{~min} \text { ) }\end{array}$ & \multirow[t]{2}{*}{$\begin{array}{c}\text { Ion channel } \\
\left(2 \mathrm{MeV} \mathrm{He}^{+} \text {beam }\right)\end{array}$} & $+\mathrm{C}$ \\
\hline & & $\begin{array}{c}\text { GaN buffer layer } \\
\text { deposited on sapphire } \\
\text { at } 600^{\circ} \mathrm{C}\end{array}$ & $\begin{array}{c}\text { Rough } \\
\text { (Both LT-layers were } \\
\text { annealed in } \mathrm{N}_{2} \text { at } \\
1000^{\circ} \mathrm{C} \text { for } 5 \mathrm{~min} \text { ) }\end{array}$ & & $+c+-c$ mix \\
\hline \multirow[t]{2}{*}{97} & \multirow[t]{2}{*}{$\begin{array}{l}\text { Smith [28] } \\
\text { (MBE) }\end{array}$} & $\begin{array}{l}\text { Sapphire nitrided for } \\
30 \mathrm{~min} \text { at } 1000^{\circ} \mathrm{C} \\
\left(\mathrm{GaN} \sim 10 \mathrm{~nm} \text { at } 685^{\circ} \mathrm{C}\right)\end{array}$ & \multirow[t]{2}{*}{$\begin{array}{c}200 \mathrm{~nm} \text { Epi-layer at } \\
775^{\circ} \mathrm{C} \text {, and then supply } \\
\mathrm{Ga}\end{array}$} & \multirow[t]{2}{*}{$\begin{array}{c}\text { Surface reconstruction } \\
\text { (e-beam) }\end{array}$} & $-\mathrm{c}$ \\
\hline & & $\begin{array}{l}\text { MOCVD-GaN on } \\
\text { sapphire }\end{array}$ & & & $+\mathrm{C}$ \\
\hline \multirow[t]{2}{*}{97} & \multirow{2}{*}{$\begin{array}{l}\text { Weyher [32] } \\
\text { (bulk GaN) }\end{array}$} & & Smooth side & \multirow{2}{*}{$\begin{array}{l}\text { Chemical stability (alkali } \\
\text { solution) }\end{array}$} & inert \\
\hline & & & Rough side & & etched \\
\hline \multirow[t]{2}{*}{97} & \multirow{2}{*}{$\begin{array}{c}\text { Seelmann-Eggebert[6] } \\
\text { (bulk GaN) }\end{array}$} & & Smooth (inert) & \multirow{2}{*}{$\begin{array}{c}\text { HSXPD } \\
\text { (photoelectron) }\end{array}$} & $+\mathrm{C}$ \\
\hline & & & Rough (etched) & & $-\mathrm{c}$ \\
\hline 98 & $\begin{array}{l}\text { Sumiya [36] } \\
\text { (MOCVD) }\end{array}$ & $\begin{array}{l}\mathrm{GaN} \text { at } 600^{\circ} \mathrm{C} \text { on non- } \\
\text { nitrided sapphire }\end{array}$ & Smooth & $\begin{array}{c}\text { CAICISS } \\
\left(2 \mathrm{keV} \mathrm{He}{ }^{+} \text {beam) }\right.\end{array}$ & $+\mathrm{C}$ \\
\hline & & $\begin{array}{l}\mathrm{GaN} \text { at } 600^{\circ} \mathrm{C} \text { on } \\
\text { nitrided sapphire }\end{array}$ & Hexagonal & & $-\mathrm{C}$ \\
\hline 98 & Shimizu [38] & Nitrided sapphire $600^{\circ} \mathrm{C}$ & N-rich (spotty RHEED) & CAICISS & $-\mathrm{C}$ \\
\hline & & $\begin{array}{c}\text { for } 5 \mathrm{mIn} \\
\left(20 \mathrm{~nm} \mathrm{GaN} \text { at } 500^{\circ} \mathrm{C}\right)\end{array}$ & $\begin{array}{l}\text { Ga-rich (streak } \\
\text { RHEED) }\end{array}$ & & $-\mathrm{C}$ \\
\hline
\end{tabular}


Table Ib. Methods for detecting relative differences depending on the polarity of the GaN.

\begin{tabular}{|c|c|c|c|c|c|}
\hline Year & $\begin{array}{l}\text { Who [Ref.] } \\
\text { (growth) }\end{array}$ & Substrate or buffer layer & $\begin{array}{l}\text { Process or Feature of } \\
\text { HT-GaN }\end{array}$ & How & Remarks \\
\hline 01 & $\begin{array}{l}\text { Jones [42] } \\
\text { (MBE) }\end{array}$ & $\begin{array}{c}\text { Sapphire } \\
\text { (AIN, none) }\end{array}$ & $\begin{array}{l}\text { Ga-rich growth } \\
+c,-c \text { on a divided } \\
\text { substrate }\end{array}$ & $\begin{array}{l}\text { Kelvin probe force } \\
\text { microscope }\end{array}$ & $\begin{array}{l}\text { +c domain }+25 \mathrm{mV} \\
-\mathrm{c} \text { domain }-30 \mathrm{mV}\end{array}$ \\
\hline 02 & $\begin{array}{l}\text { Jiang [25] } \\
\text { (MOCVD) }\end{array}$ & $\begin{array}{c}\text { Sapphire } \\
\text { (none mentioned) }\end{array}$ & +c confirmed by CBED & $\begin{array}{c}\text { atomic location by } \\
\text { channeling-enhanced } \\
\text { microanalysis } \\
\text { (e-beam) }\end{array}$ & $\begin{array}{l}\text { consistent with the } \\
\text { results by CBED }\end{array}$ \\
\hline \multirow[t]{2}{*}{02} & \multirow{2}{*}{$\begin{array}{l}\text { Koukitu }[17] \\
\text { (MOHVPE) }\end{array}$} & GaAs (111) A-face & $+C$ & \multirow{2}{*}{$\begin{array}{l}\text { Gravimetric monitoring } \\
\text { of decomposition } \\
\text { (heat) }\end{array}$} & low temp: $+c>-c$ \\
\hline & & GaAs (111) B-face & $-c$ & & high temp: $-\mathrm{c}>+\mathrm{C}$ \\
\hline \multirow[t]{2}{*}{02} & \multirow[t]{2}{*}{$\begin{array}{l}\text { Jang [44] } \\
\text { (MOCVD) }\end{array}$} & $\begin{array}{c}\text { 30nm GaN on nitrided- } \\
\text { sapphire }\end{array}$ & Smooth $(+c)$ & \multirow[t]{2}{*}{$\begin{array}{l}\mathrm{SBH} \text { measured by I-V } \\
\text { with Ti/Al contact }\end{array}$} & high \\
\hline & & $\begin{array}{c}\text { Ga pulse injection on } \\
\text { nitrided-sapphire }\end{array}$ & Hexagonal (-c) & & low \\
\hline \multirow[t]{2}{*}{02} & \multirow{2}{*}{$\underset{\text { (MBE) }}{\text { Rodriguez }}$} & GaN on sapphire & Rough (rms. 5nm) -c & \multirow{2}{*}{$\begin{array}{l}\text { Piezoresponse force } \\
\text { microscopy }\end{array}$} & $-\mathrm{C}$ \\
\hline & & 4-10nm AINonsapphir & Smooth $(0.6 \mathrm{~nm})+\mathrm{c}$ & & $+\mathrm{C}$ \\
\hline \multirow[t]{2}{*}{03} & \multirow{2}{*}{$\begin{array}{c}\text { Cros [41] } \\
\text { (MBE) }\end{array}$} & GaN on sapphire & Rough (rms. 5nm) & \multirow[t]{2}{*}{ Raman } & Strong $\mathrm{A} 1(\mathrm{TO}) 534 \mathrm{~cm}^{-1}$ \\
\hline & & $\begin{array}{l}\text { 4-10nm AIN on } \\
\text { sapphire }\end{array}$ & Smooth (0.6nm) & & Strong A1(LO) $739 \mathrm{~cm}^{-1}$ \\
\hline
\end{tabular}


Table IIa. Relationship between the growth condition and the polarity of GaN deposited on sapphire substrates by MBE. The table shows the list of research groups, each of which has their own know-how on regarding growth.

\begin{tabular}{|c|c|c|c|c|c|c|}
\hline $\begin{array}{l}\text { Group [Ref.] } \\
\text { (polarity) }\end{array}$ & Nitridation source & $\begin{array}{l}\text { Nitridation } \\
\text { temperature }\end{array}$ & Phenomena & $\begin{array}{c}\text { Buffer layer } \\
\text { condition }\end{array}$ & Epi-layer & polarity \\
\hline \multirow{3}{*}{$\begin{array}{l}\text { Crete Univ. [54] } \\
\text { (RHEED) }\end{array}$} & \multirow{3}{*}{\begin{tabular}{|l|} 
N-radical for 100min \\
$500 W$ plasma \\
(N exist from AES)
\end{tabular}} & \multirow{2}{*}{ at $750^{\circ} \mathrm{C}$} & \multirow{2}{*}{$\begin{array}{l}\text { Roughened, } \\
\text { increase of lattice by } \\
6 \%\end{array}$} & $16 \mathrm{~nm} \mathrm{GaN}$ at $350^{\circ} \mathrm{C}$ & & $+c$ \\
\hline & & & & $\begin{array}{l}16 \mathrm{~nm} \mathrm{GaN} \text { at } 350^{\circ} \mathrm{C} \\
\text { and then, annealed } \\
\text { at } 700^{\circ} \mathrm{C}\end{array}$ & & $-\mathrm{C}$ \\
\hline & & at $200^{\circ} \mathrm{C}$ & $\begin{array}{l}\text { Smoothing, } \\
\text { increase of lattice by } \\
9 \%\end{array}$ & 16nm AIN & & $+\mathrm{C}$ \\
\hline \multirow{5}{*}{$\begin{array}{l}\text { Georgia Inst. of } \\
\text { Tech. [62] } \\
\text { (SP-EFM, RHEED)) }\end{array}$} & \multirow[t]{5}{*}{$\mathrm{N}$-radical for $1 \mathrm{~h}$} & \multirow[t]{3}{*}{ at $700^{\circ} \mathrm{C}$} & \multirow[t]{3}{*}{6 Å AIN [55] } & $30 \mathrm{~nm} \mathrm{GaN}$ at $500^{\circ} \mathrm{C}$ & \multirow[t]{5}{*}{$0.9 \mathrm{~m} / \mathrm{h} 615^{\circ} \mathrm{C}$} & $-c$ \\
\hline & & & & 12nm AIN & & -c (IDs) \\
\hline & & & & 30nm AIN & & $+\mathrm{C}$ \\
\hline & & \multirow[t]{2}{*}{ at $200^{\circ} \mathrm{C}$} & \multirow[t]{2}{*}{$23 \AA ̊ A I N+N O$} & $30 \mathrm{~nm} \mathrm{GaN}$ at $500^{\circ} \mathrm{C}$ & & + +c(IDs) \\
\hline & & & & $\begin{array}{l}2-67 \mathrm{~nm} \text { AIN at } 700- \\
850^{\circ} \mathrm{C}\end{array}$ & & $+c$ \\
\hline \multirow{7}{*}{$\begin{array}{l}\text { Virginia } \\
\text { Commonwealth } \\
\text { Univ. [65] }\left(\mathrm{H}_{3} \mathrm{PO}_{4} \text {, }\right. \\
\text { RHEED) }\end{array}$} & \multirow[t]{7}{*}{ N-radical } & \multirow{7}{*}{$\begin{array}{l}\text { at } 890-985^{\circ} \mathrm{C} \text {, and } \\
500^{\circ} \mathrm{C}\end{array}$} & \multirow{7}{*}{$\begin{array}{l}\text { No effect of the } \\
\text { nitridation } \\
\text { temperature on } \\
\text { polarity }\end{array}$} & $\begin{array}{l}\text { 30-40nm GaN } \\
\left(0.6 \mathrm{~m} / \mathrm{h} \text { at } 500^{\circ} \mathrm{C}\right.\end{array}$ & \multirow[t]{7}{*}{$\begin{array}{l}\text { Ga-rich } 0.3-1 \mathrm{~m} / \\
\text { h720-850 }\end{array}$} & $-\mathrm{c}$ \\
\hline & & & & $\begin{array}{l}60-150 \mathrm{~nm} \mathrm{GaN} \\
\left(0.6 \mathrm{~m} / \mathrm{h} \text { at } 500^{\circ} \mathrm{C}\right.\end{array}$ & & $+c$ \\
\hline & & & & \begin{tabular}{|l|}
$110-220 \mathrm{~nm} \mathrm{GaN}$ \\
$\left(0.22 \mathrm{~m} / \mathrm{h}\right.$ at $\left.500^{\circ} \mathrm{C}\right)$
\end{tabular} & & $-\mathrm{c}$ \\
\hline & & & & $\mathrm{GaN}$ at $800^{\circ} \mathrm{C}$ & & $-\mathrm{c}$ \\
\hline & & & & $\begin{array}{l}20 \mathrm{~nm} \text { AIN at } 500^{\circ} \mathrm{C} \\
20-30 \mathrm{~nm} / \mathrm{h}\end{array}$ & & $-\mathrm{c}$ \\
\hline & & & & $\begin{array}{l}20 \mathrm{~nm} \text { AIN at } 500^{\circ} \mathrm{C} \\
60 \mathrm{~nm} / \mathrm{h}\end{array}$ & & $+c$ \\
\hline & & & & $\begin{array}{l}\text { 20nmAlN at 890- } \\
930^{\circ} \mathrm{C}\end{array}$ & & $+\mathrm{C}$ \\
\hline \multirow{3}{*}{$\begin{array}{l}\text { Walter Schottky } \\
\text { Inst, and Cornell } \\
\text { Univ. [60] } \\
\text { (KOH) }\end{array}$} & \multirow[t]{3}{*}{ Non-nitridation } & & & $15 \mathrm{~nm} \mathrm{GaN}$ at $800^{\circ} \mathrm{C}$ & \multirow[t]{3}{*}{ at $800^{\circ} \mathrm{C}$} & $-\mathrm{C}$ \\
\hline & & & & $0-5 \mathrm{~nm}$ AIN at $800^{\circ} \mathrm{C}$ & & $\begin{array}{ll}-C \\
\end{array}$ \\
\hline & & & & $\begin{array}{l}\text { 5-15nm AIN at } 800 \\
{ }^{\circ} \mathrm{C}\end{array}$ & & $+\mathrm{C}$ \\
\hline \multirow{6}{*}{$\begin{array}{l}\text { Cal. Inst. of Tech. } \\
\text { [61] } \\
(\mathrm{KOH})\end{array}$} & \multirow[t]{6}{*}{$\mathrm{N}$-radical for $30 \mathrm{~min}$} & \multirow[t]{6}{*}{ at $800^{\circ} \mathrm{C}$} & \multirow[t]{6}{*}{ formation of AIN } & 5-8nm GaN & N-rich & \multirow[t]{3}{*}{$-\mathrm{C}$} \\
\hline & & & & & $\mathrm{V} / \mathrm{III}=1$ & \\
\hline & & & & & Ga-rich & \\
\hline & & & & $\begin{array}{l}\text { 5-8nm AIN under Al- } \\
\text { rich }\end{array}$ & \multirow[t]{3}{*}{ Slightly Ga-rich } & \multirow[t]{3}{*}{$+c$} \\
\hline & & & & $\begin{array}{l}\text { 5-8nm AIN under V/ } \\
I I I=1\end{array}$ & & \\
\hline & & & & $\begin{array}{l}\text { 5-8nm AIN under N- } \\
\text { rich }\end{array}$ & & \\
\hline \multirow{5}{*}{$\begin{array}{l}\text { AIST } \\
\text { (RHEED, CAICISS) }\end{array}$} & & & & $20 \mathrm{~nm} \mathrm{GaN}$ at $700^{\circ} \mathrm{C}$ & $700^{\circ} \mathrm{C}$ & $-\mathrm{C}$ \\
\hline & plasma for $5 \mathrm{~min}$ at & & & $20 \mathrm{~nm} \mathrm{GaN}$ at $500^{\circ} \mathrm{C}$ & $(0.6 \mathrm{~m} / \mathrm{h})$ & $-\mathrm{C}$ \\
\hline & & & & $20 \mathrm{~nm}$ AIN at $700^{\circ} \mathrm{C}$ & & $\begin{array}{l}-C \\
\end{array}$ \\
\hline & & & & $20 \mathrm{~nm}$ AIN at $500^{\circ} \mathrm{C}$ & & $+c$ \\
\hline & $\begin{array}{l}\text { No-cracking } \mathrm{NH}_{3} \\
5 \mathrm{sccm} \text { for 30min at } \\
910^{\circ} \mathrm{C}[56]\end{array}$ & & & $20 \mathrm{~nm} \mathrm{GaN}$ at $500^{\circ} \mathrm{C}$ & $100 \mathrm{~nm}$ at $820^{\circ} \mathrm{C}$ & \begin{tabular}{|l|}
$+\mathrm{C}$ \\
(-c without $\mathrm{NH}_{3}$ \\
treatment)
\end{tabular} \\
\hline $\begin{array}{l}\text { Univ. of Minnesota } \\
\text { [29] } \\
\text { (RHEED) }\end{array}$ & $\begin{array}{l}\mathrm{NH}_{3} \text { flow }\left(1 \times 10^{-}\right. \\
5 \text { Torr) for } 15 \mathrm{~min}\end{array}$ & from 500 to $1000^{\circ} \mathrm{C}$ & & $\mathrm{GaN}$ at $700^{\circ} \mathrm{C}$ & & $-c$ \\
\hline & for 3min & & & $25 \mathrm{~nm}$ AIN at $1000^{\circ} \mathrm{C}$ & & $+C$ \\
\hline & for $15 \mathrm{~min}$ & & & & & mixed \\
\hline
\end{tabular}


Table IIb. List of reports claiming polarity conversion from $-\mathrm{c}$ to $+\mathrm{c}$ MBE-GaN by insertion of a metal layer.

\begin{tabular}{|c|c|c|c|c|}
\hline \begin{tabular}{|l}
$\begin{array}{l}\text { Group[Ref.] } \\
\text { (polarity) }\end{array}$ \\
\end{tabular} & $\begin{array}{l}\text { Nitridation } \\
\text { condition }\end{array}$ & $\begin{array}{l}\text { Buffer layer } \\
\text { condition }\end{array}$ & Epi-layer & polarity \\
\hline \multirow{2}{*}{$\begin{array}{l}\text { Chiba Univ. } \\
\text { [66] } \\
\text { (CAICISS) }\end{array}$} & \multirow{2}{*}{$\begin{array}{l}\mathrm{N} \text {-radical at } \\
200^{\circ} \mathrm{C} \text { for } \\
40 \mathrm{~min}\end{array}$} & $\begin{array}{l}20 \mathrm{~nm} \text { GaN at } \\
650^{\circ} \mathrm{C}\end{array}$ & \multirow[t]{2}{*}{ at $820^{\circ} \mathrm{C}$} & $-c$ \\
\hline & & $\begin{array}{l}\text { Al thin layer } \\
\text { after 100nm } \\
\text { epi-GaN }\end{array}$ & & $+\mathrm{C}$ \\
\hline \multirow{2}{*}{\begin{tabular}{|l|} 
Dongguk \\
Univ. [68] \\
(RHEED)
\end{tabular}} & \multirow{2}{*}{\begin{tabular}{|l|} 
N-radical at \\
$500^{\circ} \mathrm{C}$ for \\
$10 \mathrm{~min}, 250 \mathrm{~W}$ \\
plasma
\end{tabular}} & AIN at $850^{\circ} \mathrm{C}$ & \multirow{2}{*}{$\begin{array}{l}800^{\circ} \mathrm{C} 0.9 \mathrm{~m} / \\
\mathrm{h}\end{array}$} & $-\mathrm{C}$ \\
\hline & & $\begin{array}{l}\text { Al metal }(\sim 6 \\
\text { layers) +AIN }\end{array}$ & & $\begin{array}{l}+\mathrm{C} \text { when } \mathrm{Al} 2 \\
\text { layers }\end{array}$ \\
\hline \multirow[t]{2}{*}{$\begin{array}{l}\text { Sophia Univ. } \\
{[69]} \\
(\mathrm{KOH})\end{array}$} & Non-nitrided & $\begin{array}{l}10 \mathrm{~nm} \text { AIN at } \\
750^{\circ} \mathrm{C} \\
\text { (alternative } \\
\text { supply of } \mathrm{Al}, \\
\mathrm{N} \text { source, } \\
\text { MEE) }\end{array}$ & \multirow[t]{2}{*}{$\begin{array}{l}\text { MEE of } \mathrm{Ga} \text {, } \\
\mathrm{N} \text { at } 750^{\circ} \mathrm{C}\end{array}$} & $+c$ \\
\hline & \begin{tabular}{|l|} 
Nitridation \\
\end{tabular} & non & & $-\mathrm{C}$ \\
\hline $\begin{array}{l}\text { Furukawa } \\
\text { Elcetric Co. } \\
\text { Ltd. [70] }\end{array}$ & \begin{tabular}{|l|} 
Non- \\
nitridation
\end{tabular} & $\begin{array}{l}\text { Ga metal (2 } \\
\text { layers) + } \\
50 \mathrm{~nm} \text { GaN at } \\
700^{\circ} \mathrm{C}\end{array}$ & $\begin{array}{l}850^{\circ} \mathrm{C} \\
1.5 \mathrm{~m} / \mathrm{h}\end{array}$ & $+c$ \\
\hline
\end{tabular}


Table III. GaN samples grown on sapphire substrates by HVPE. Relationship between surface morphology and the initial growth on the substrate is summarized.

\begin{tabular}{|c|c|c|c|}
\hline Year & Who [Ref.] & $\begin{array}{l}\text { Initial growth } \\
\text { condition }\end{array}$ & Morphology \\
\hline \multirow[t]{2}{*}{90} & \multirow[t]{2}{*}{ Naniwae [95] } & $\begin{array}{l}\mathrm{Ga}+\mathrm{HCl} \\
\text { treatment of } \\
\text { sapphire sub. at } \\
1030^{\circ} \mathrm{C}<70 \mathrm{ml} / \\
\text { min for } 10 \mathrm{~min}\end{array}$ & rough + pit \\
\hline & & $\begin{array}{l}\mathrm{Ga}+\mathrm{HCl} \\
\text { treatment of } \\
\text { sapphire sub. at } \\
1030^{\circ} \mathrm{C}>70 \mathrm{ml} / \\
\text { min for } 20 \mathrm{~min}\end{array}$ & smooth \\
\hline \multirow[t]{2}{*}{92} & \multirow[t]{2}{*}{$\begin{array}{l}\text { Detchprochm } \\
\text { [96] }\end{array}$} & $\begin{array}{l}\text { Sputtered } \mathrm{ZnO} \\
\text { buffer }\end{array}$ & $\begin{array}{l}\text { smooth + } \\
\text { transparent }\end{array}$ \\
\hline & & Direct growth & granular \\
\hline \multirow[t]{2}{*}{97} & \multirow[t]{2}{*}{ Molnar [97] } & Direct growth & hexagonal facet \\
\hline & & $\begin{array}{l}\mathrm{ZnO} \text { or } \mathrm{GaCl} \\
\text { treatment }\end{array}$ & smooth \\
\hline \multirow[t]{2}{*}{97} & \multirow[t]{2}{*}{ Lee [98] } & $\begin{array}{l}\text { Sputtered 50nm } \\
\text { AIN at }<960^{\circ} \mathrm{C}\end{array}$ & rough \\
\hline & & $\begin{array}{l}\text { Sputtered 50nm } \\
\text { AIN at } 980- \\
1020^{\circ} \mathrm{C}\end{array}$ & $\begin{array}{l}\text { Relatively } \\
\text { smooth }\end{array}$ \\
\hline \multirow[t]{3}{*}{99} & \multirow[t]{3}{*}{ Paskova [99] } & $\begin{array}{l}\text { Nitrided a-plane } \\
\text { sapphire }\end{array}$ & hillocks \\
\hline & & $\mathrm{GaCl}$ treatment & hillocks \\
\hline & & $\begin{array}{l}\text { Magnetron- } \\
\text { sputtered } 50 \mathrm{~nm} \\
\text { AIN at } 1000^{\circ} \mathrm{C} \\
\text { on a-plane } \\
\text { sapphire }\end{array}$ & Smooth with pits \\
\hline \multirow[t]{5}{*}{99} & \multirow[t]{5}{*}{ Wagner [100] } & Direct growth & hillock \\
\hline & & $\begin{array}{l}\text { GaN }(<10 \mathrm{~nm}) \\
\text { buffer layer by } \\
\text { MOCVD at } \\
600^{\circ} \mathrm{C}\end{array}$ & hexagonalfacets \\
\hline & & $\begin{array}{l}\text { GaN (>10nm) } \\
\text { buffer layer by } \\
\text { MOCVD at } \\
600^{\circ} \mathrm{C}\end{array}$ & smoothest \\
\hline & & $\begin{array}{l}\text { AIN buffer layer } \\
\text { by MOCVD at } \\
600^{\circ} \mathrm{C}\end{array}$ & smooth \\
\hline & & $\begin{array}{l}\text { GaN (20 to } \\
200 n m) \text { buffer } \\
\text { layer by HVPE at } \\
650^{\circ} \mathrm{C}\end{array}$ & $\begin{array}{l}\text { truncated } \\
\text { pyramids }\end{array}$ \\
\hline 00 & Tavernier [101] & $\begin{array}{l}0.1 \mathrm{~m} \text { GaN buffer } \\
\text { by HVPE at } \\
550^{\circ} \mathrm{C} \text { on } \\
\text { sapphire, and } \\
\text { then two-step } \\
\text { growth at } 1050- \\
1100^{\circ} \mathrm{C} \text {. }\end{array}$ & smooth \\
\hline
\end{tabular}

Table III. GaN samples grown on sapphire substrates by HVPE. Relationship between surface morphology and the initial growth on the substrate is summarized.

\begin{tabular}{|c|c|c|c|}
\hline \multirow[t]{3}{*}{02} & \multirow[t]{3}{*}{ Zhang [106] } & $\begin{array}{l}\text { HT-GaN buffer } \\
\text { on c-sapphire } \\
\text { treated by } \mathrm{GaCl} \\
\text { at } 800-1050^{\circ} \mathrm{C} \\
\text { without } \mathrm{HT}-\mathrm{GaN}\end{array}$ & $\begin{array}{l}\operatorname{TD}\left(\mathrm{cm}^{-2}\right): 10^{9}, \\
\text { rms:4.1 }\end{array}$ \\
\hline & & $\begin{array}{l}\text { HT-GaN buffer } \\
\text { on c-sapphire } \\
\text { treated by } \mathrm{GaCl} \\
\text { at } 800-1050^{\circ} \mathrm{C} \\
\text { with } \mathrm{HT}-\mathrm{GaN}\end{array}$ & $\begin{array}{l}\operatorname{TD}\left(\mathrm{cm}^{-2}\right): 10^{8}, \\
\text { rms:0.5 }\end{array}$ \\
\hline & & $\begin{array}{l}\text { HT-GaN buffer } \\
\text { on c-sapphire } \\
\text { treated by } \mathrm{GaCl} \\
\text { at } 800-1050^{\circ} \mathrm{C} \\
\text { with + flow } \\
\text { modulation }\end{array}$ & $\begin{array}{l}\operatorname{TD}\left(\mathrm{cm}^{-2}\right): 10^{7}, \\
\mathrm{rms}: 1.4\end{array}$ \\
\hline
\end{tabular}

